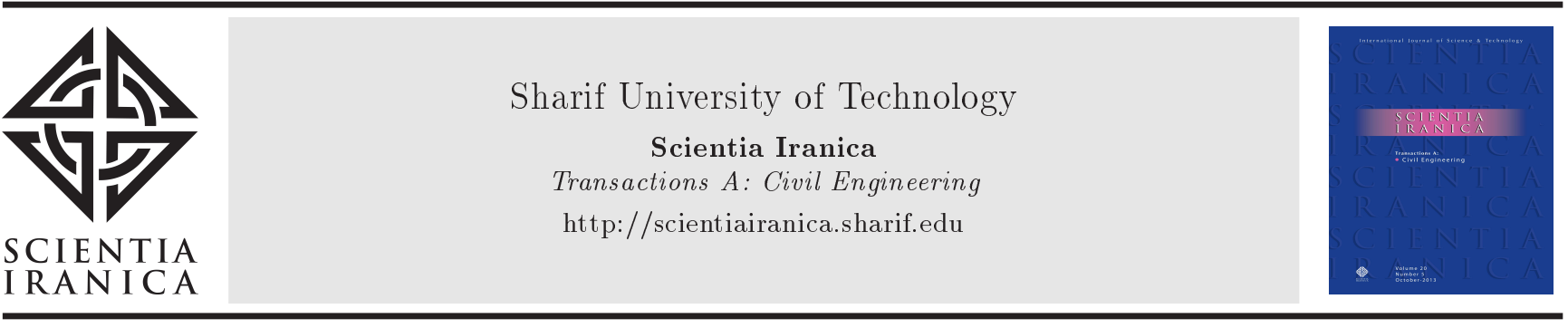

\title{
Comparison of adaptive magnetorheological elastomer isolator and elastomeric isolator in near-field and far-field earthquakes
}

\author{
S. Taghizadeh and A. Karamodin* \\ Department of Civil Engineering, Ferdowsi University of Mashhad, Mashhad, P.O. Box 9177948944-1111, Iran.
}

Received 17 December 2017; received in revised form 17 December 2018; accepted 16 February 2019

\author{
KEYWORDS \\ Magnetorheological \\ elastomer (MRE) \\ isolator; \\ Base-isolated \\ benchmark building; \\ Near-field earthquake; \\ Far-field earthquake; \\ Magnetorheological \\ (MR) damper.
}

\begin{abstract}
Magnetorheological Elastomers (MREs) are widely used in the development of smart isolators and absorbers due to their stiffness and damping adaptability. This study investigates the performance of MRE isolators and elastomeric isolators in both nearfield and far-field earthquakes in base-isolated benchmark buildings. All earthquakes were simultaneously investigated in two horizontal directions on the horizontal plane. Vertical earthquakes were not considered in the dynamic analysis of base-isolated benchmark buildings. The effect of bilateral interaction was also examined while making an isolator model. Moreover, the behaviors of MRE isolators and Magnetorheological (MR) dampers were compared. To this end, three control systems including adaptive isolator, passive isolator, and semi-active MR damper were taken into account. The results showed that the MRE isolator outperformed the elastomeric isolator in near-field earthquakes due to its variable stiffness and damping. In addition, the semi-active MR damper for both far-field and near-field earthquakes significantly reduced base displacement; however, it increased floor accelerations, story drifts, and story shear. The results of this study showed that MRE isolator could be an appropriate substitute for MR damper. The MRE isolator could reduce base displacement without increasing other responses.
\end{abstract}

(C) 2021 Sharif University of Technology. All rights reserved.

\section{Introduction}

Seismic isolator is one of the best techniques for protecting structures against severe earthquakes [1-3]. In this technique, the effects of earthquakes, especially in frequencies that cause severe damages to structures, reduce structural damages by separating the structure from ground vibration. The seismic isolator system

*. Corresponding author. Tel.: +985138805000 E-mail addresses: saeed.taghezadeh@mail.um.ac.ir (S. Taghizadeh); a-karam@um.ac.ir (A. Karamodin)

doi: $10.24200 /$ sci. 2019.50039 .1478 has been widely implemented in many countries over the past three decades [4-7].

The design of traditional seismic isolators depends on the magnitude and frequency of earthquakes. The results indicate that the traditional seismic isolation system would not perform well when exposed to different types of earthquakes. In other words, it may have successful performance in one earthquake and disappointing performance in another. Therefore, the adaptability of a seismic isolator system is a major concern in seismic applications $[8,9]$. Recent researches have revealed that seismic isolators are likely to be damaged by both near-field [10-13] and far-field earthquakes [13,14]. In near-field earthquakes, such as 
the 1994 Northridge earthquake, large displacements and long-period pulses make the seismic isolator overstretched and damage the whole system [11-15]. Farfield earthquakes with contents of low frequency may cause a resonance phenomenon in the seismic isolator structure; thus, the seismic isolator aggravates the responses and causes structural failure instead of reducing the dynamic responses [14]. Yaghmaei-Sabegh et al. [16] investigated the inelastic displacement ratio of base-isolated structures. To this end, a two-degreeof-freedom model was employed. Inelastic behavior was observed in both isolators and superstructure. Moreover, the effect of the properties of isolators and superstructure on the inelastic displacement ratio based on two sets of near-fault and far-fault ground motions was considered. A straightforward approximate method for estimating the inelastic displacement ratio for baseisolated structures exposed to near-fault and far-fault ground motions was developed by Yaghmaei-Sabegh et al. [17]. Vertical distribution of the lateral seismic force on the base-isolated structures was investigated by Rofooei and Ebrahimi [18]. In another study, 3D base-isolated structural models with Laminated Rubber Bearing (LRB) isolators were investigated by considering a variety of effective damping and period ratios. The results showed that the base shear force recommended by UBC97 was reasonably accurate.

The most commonly used isolators are LRB [19,20], Lead Core Rubber Bearing (LCRB) [20], and High Damping Rubber Bearing (HDRB) [21]. In designing these isolators, the geological conditions and performances of the structure are of significance [3]. Due to the passive nature of the traditional rubber, the rubber properties, i.e., stiffness and damping, do not change; however, when the structure is exposed to earthquakes, the aforementioned problems may arise. In order to increase the adaptability of passive baseisolated systems, researchers [22-24] have proposed several techniques including implementing supplementary energy dissipation devices such as MR dampers, friction dampers, and hydraulic fluid dampers to reduce structural responses. These methods are classified into various hybrid base isolation systems which are regarded as possible solutions to solve the problems in such systems. Incorporating supplemental energy dissipation devices to the base isolation system can cause several problems [11-15]. Reducing base displacement significantly increases story drifts and floor accelerations. In addition, hybrid base isolation systems complicate the design, implementation, and reliability of the systems. Moreover, the proposed hybrid base isolation systems may not be able to perform well in far-field earthquakes since they are designed based on a fixed natural frequency; therefore, the frequency compatibility is not tuned in real conditions. Malekzadeh and Taghikhany [25] investigated two isolated structures with FPS and Double Concave Friction Pendulum (DCFP) at three different hazard levels of SLE, DBE, and MCE. The results indicated that in comparison with the isolated buildings with the FPS bearing at SLE and DBE levels, DCFP could significantly reduce the peak floor acceleration and peak inter-story drift of the superstructure. Since stiffness and damping varied during ground motion, DCFP acted as an adaptive isolation system and can control the peak floor acceleration and inter-story drift simultaneously.

Development of Magnetorheological Elastomer (MRE) overcomes the major shortcomings of traditional base isolation systems and creates a new type of seismic isolators whose stiffness and damping can be controlled in real conditions. MRE is the new generation of MR materials in which stiffness and damping are changed by a magnetic field in real time $[26,27]$. MRE shares some similarities with a soft rubber in the absence of a magnetic field. Due to the effect of the magnetic field strength, the MRE material modulus can significantly increase. The maximum variation of the MRE modulus ranges from approximately $50 \%$ (for stiffer rubber carrier) to over $300 \%$ (for soft rubber carrier like silicone gel) $[28,29]$. According to a study conducted by Chen et al., the maximum variation of the MRE damping ranges from approximately $10 \%$ to $32 \%$, depending on the type of rubber matrix, percentage of iron particles, and strength of the magnetic field [30]. MRE materials are applied to various engineering projects and are referred to as new tools for mitigation and vibration control.

Although the research on and development of MRE materials have progressed in recent years, the scope of studies on the applications of MRE materials, especially the development of MRE devices and their implementation, is quite limited. Behrooz et al. [31] proposed a semi-active/-passive isolator called variable stiffness and damping isolator, which could reduce structural vibration. The experimental results indicated that stiffness increased by about $30 \%$. Opie and Yim [32] proposed a variable stiffness vibration isolator and the experimental results indicated that the MRE isolator reduced the payload velocity by $16 \%$ to $30 \%$. Li et al. proposed an adaptive seismic isolator to challenge the problem of traditional isolators against far-field and near-field earthquakes [33]. MRE materials are employed for new isolators. Experimental tests were conducted on a shaking table under harmonic cycling loading to consider the MRE isolator behavior. Experimental results indicated that damping force and lateral stiffness could change in real time up to $45 \%$ and $37 \%$, respectively. $\mathrm{Li}$ and $\mathrm{Li}$ [34] developed a novel adaptive seismic isolation system. Experimental results showed that the lateral stiffness increased up to $1630 \%$. Li et al. [35] developed a new 
highly adjustable MRE base isolator. Shear modulus could be highly adjustable by means of a mediumlevel magnetic field. To consider the characteristics and performance of this new adaptive MRE isolator, comprehensive static and dynamic testing were conducted. The experimental results demonstrated that lateral stiffness of the isolator up to $1630 \%$ could vary by the medium-level magnetic field. Zhao et al. [36] investigated the characteristics of the MRE isolator in different loading conditions. The experimental results showed that effective stiffness increased up to $114.12 \%$ with the current increasing from $0 \mathrm{~A}$ to $3 \mathrm{~A}$. $\mathrm{Gu}$ et al. [37] evaluated the performance of the MRE isolator numerically on a five-story building model. To this end, three different building systems including a bare building, a building with passive base isolation, and a building with the adaptive base isolation system were evaluated. A Linear Quadratic Regulation (LQR) control law was applied to the adaptive base isolation system. Simulation results indicated that the adaptive base isolation system could be superior to other two systems in different earthquakes. Although the passive base isolation system can efficiently reduce floor accelerations, it fails to reduce inter-story drifts. While the performance of the passive base isolated model is highly dependent on the nature of earthquakes, the adaptive base isolation system performs well in reducing floor accelerations, inter-story drifts, and base shear. Gu et al. [38] proposed a smart base isolation system and employed MRE isolators and a frequency control algorithm, which shifted the fundamental frequency of the structure away from the dominant frequency of earthquakes. This design keeps the building away from the resonance state. Simulation of a five-story building model was conducted and its results indicated that the proposed control system could reduce floor accelerations, inter-story drifts, and base shear under different types of earthquake attacks. $\mathrm{Gu}$ et al. [39] proposed a semi-active-story isolation system in which MRE isolators were utilized. The MRE isolators were installed under each story of the structure rather than beneath the entire structure. Then, the five-story building model was simulated. The results showed that the proposed control system could reduce floor accelerations, inter-story drifts, and base shear under different types of earthquake. In addition, the structural stiffness of each floor in this system was easily controlled by the applied current to each isolator. $\mathrm{Gu}$ et al. [40] investigated the inherent response time of the MRE isolator and developed two practical approaches to minimize the response time delay. The proposed approaches to minimizing the time delay were:

(i) The transient response of shear force from the MRE isolator;

(ii) Transient response of the current of a large coil that generated the magnetic field. The results illustrated that the proposed approaches were promising and impressive.

Yang et al. [41] investigated the performance of a stiffness softening MRE isolator in a scaled threestory building. The current signals to the isolators based on real-time responses of the building floors were calculated by a fuzzy controller. Prior to the experimental test, the feasibility of the closed-loop control system was evaluated through simulation. The experimental results and simulation showed that the stiffness softening MRE isolator could significantly mitigate the structural vibration.

To describe the behavior of MRE materials, different models have been proposed by researchers. The proposed models should be able to show the force displacement curve and nonlinear relation between force and velocity and conform to the results of experimental tests. Jolly et al. [42] proposed a quasi-static model in which the modulus increased as a result of an increase in the magnetic field and interaction among the adjacent particles. Davis [43] employed finite element methods for analyzing any increase in the modulus under varying magnetic fields. The inverse model for the MRE base isolator was proposed by $\mathrm{Gu}$ et al. [44] that was based on an optimal General Regression Neural Network (GRNN). The testing results indicated that the desired control force reproduced by the GRNN inverse model was accurate. $\mathrm{Li}$ et al. [45] proposed a four-parameter viscoelastic model to examine the behavior of MRE materials. In this modeling, a spring element was added parallel to the solid standard three-parameter model, indicating that the modulus was dependent on the magnetic field. Yang et al. [46] proposed a new model to show the behavior of MRE isolators. This model included the Bouc-Wen component that reproduced hysteresis loops in parallel with the Viogt element, which described the behaviors of solid materials.

The present study employed the model proposed by yang et al. [46]. Due to the reception of the baseisolated benchmark buildings by the ASCE Control Committee, they are used to compare the behavior of MRE isolator and other isolators. Given that the threedimensional structure of the base-isolated benchmark buildings is of significance, the effects of bilateral interaction are considered in isolation modeling. This study examines the effects of near-field and far-field earthquakes on passive isolation systems, hybrid systems, and adaptive isolator systems.

\section{Base-isolated benchmark building}

The base-isolated benchmark building is an eight-story building with a steel-braced frame. The length, width, 


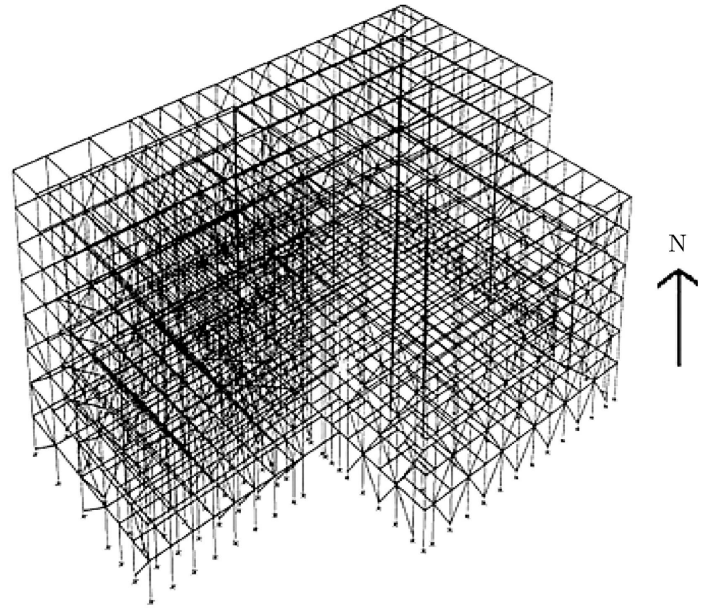

(a)

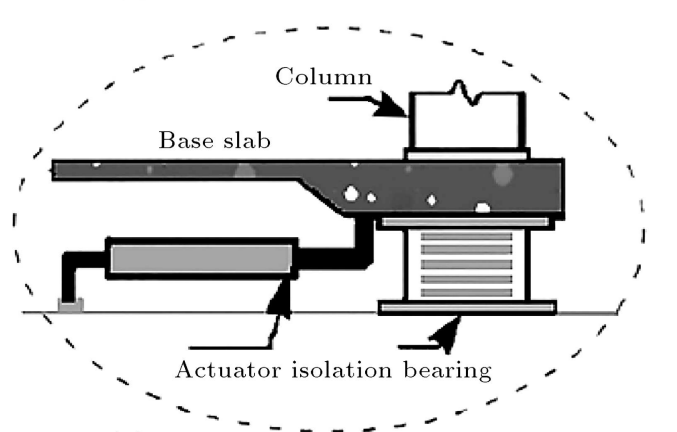

(b)

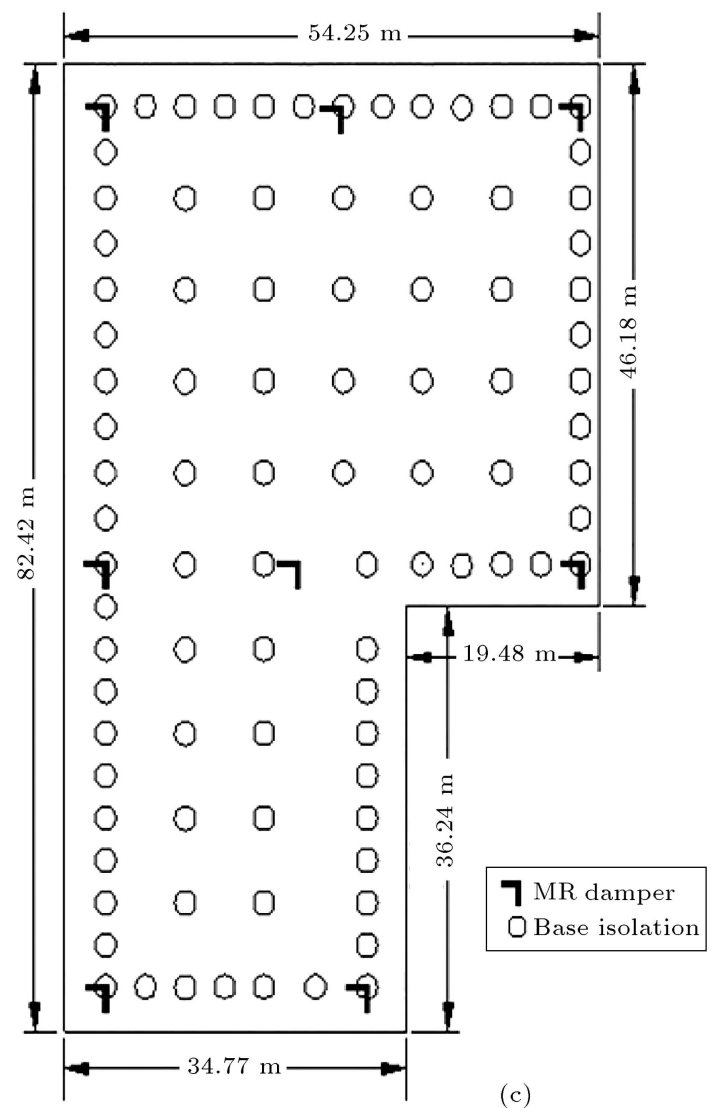

Figure 1. (a) The three-dimensional model of the benchmark building. (b) The elevation view of the control devices. (c) The plan of the base of the benchmark building which illustrates the location of the isolators and Magnetorheological (MR) dampers [47].

Table 1. Periods of the benchmark building [47].

\begin{tabular}{cccccccccc}
\hline & \multicolumn{3}{c}{ North-South } & \multicolumn{3}{c}{ East-West } & \multicolumn{3}{c}{ Torsional } \\
\hline Mode & 1 & 2 & 3 & 1 & 2 & 3 & 1 & 2 & 3 \\
Period & 0.78 & 0.27 & 0.15 & 0.89 & 0.28 & 0.15 & 0.66 & 0.21 & 0.12 \\
\hline
\end{tabular}

and the story height of the building are $84.8 \mathrm{~m}, 54.3 \mathrm{~m}$, and $4.04 \mathrm{~m}$, respectively, similar to a hospital building in Los Angeles, California. The plan from the first to the sixth floor is L-shaped and rectangular for the seventh and eighth floors. Braces are located at the building perimeter. Metal decking and a grid of steel beams support all concrete floor slabs. The steel superstructure is supported on a reinforced concretebased slab which is integral to the concrete beams below and drop panels under each of column locations. The isolators are connected between these drop panels and the footing below, as shown in Figure 1. The structure is composed of linear elements of beams, columns, braces, and rigid slabs. The superstructure is modeled as a shear structure with linear elastic behavior in three dimensions. The floor slabs and base mat are assumed rigid. The superstructure and base have three degrees of freedom at the center of the mass per floor. The combined building model has 27 degrees of freedom, 24 degrees of which are for the superstructure and 3 degrees for the isolation system. All 24 modes in the fixed base case are employed in modeling the superstructure. The damping ratio of the superstructure in all fixed base modes is $5 \%$. The superstructure is a linear elastic system with lateral torsional behavior in dynamic analysis. The periods of the first three modes of the structure are shown in Table 1. The isolation system consists of 92 seismic isolators on the structure base. In addition, there are $16 \mathrm{MR}$ dampers on the structure base, eight in the direction of the $X$ axis and eight in $Y$ axis. Figure 1 presents the three-dimensional model of the benchmark building, elevation view of the control devices, and location of the elastomeric isolators and MR dampers [47-51].

The equation of motion for the elastic superstruc- 
ture is expressed in the following matrix:

$$
M \ddot{U}+C \dot{U}+K U=-M R\left(\ddot{U}_{g}+\ddot{U}_{b}\right)
$$

where $M$ is the superstructure lumped mass matrix with a size of $24 \times 24, C$ is the superstructure damping matrix with a size of $24 \times 24$ in the fixed base case, $K$ is the superstructure stiffness matrix with a size of $24 \times 24$ in the fixed base case, and $R$ is the matrix of earthquake influence coefficients with a size of $24 \times 3$. Furthermore, $\ddot{U}, \dot{U}$, and $U$ are the floor acceleration, velocity, and displacement vectors relative to the base, respectively. These vectors have 24 entries. $\ddot{U}_{b}$ and $\ddot{U}_{g}$ with a size of $3 \times 1$ show the vector of base accelerations relative to the ground and vector of ground accelerations, respectively. The equation related to the base mass motion can be written as follows:

$$
R^{T} M\left[\ddot{U}+R\left(\ddot{U}_{g}+\ddot{U}_{b}\right)\right]+M_{b}\left(\ddot{U}_{g}+\ddot{U}_{b}\right)+f_{B}=0,
$$

where $M_{b}$ is a $3 \times 3$ matrix showing the diagonal mass matrix of the rigid base slab. Moreover, $f_{B}$ denotes the $3 \times 1$ nonlinear force vector corresponding to the isolators. These forces are applied to the center of the base slab mass. The above equations can be expressed as:

$$
\begin{aligned}
& {\left[\begin{array}{cc}
M & M R \\
R^{T} M & R^{T} M R^{T}+M_{b}
\end{array}\right]\left\{\begin{array}{c}
\ddot{U} \\
\ddot{U}_{b}
\end{array}\right\}+\left[\begin{array}{cc}
C & 0 \\
0 & 0
\end{array}\right]\left\{\begin{array}{c}
\dot{U} \\
\dot{U}_{b}
\end{array}\right\}} \\
& +\left[\begin{array}{cc}
K & 0 \\
0 & 0
\end{array}\right]\left\{\begin{array}{c}
U \\
U_{b}
\end{array}\right\}+\left\{\begin{array}{c}
0 \\
f_{B}
\end{array}\right\}=-\left[\begin{array}{c}
M R \\
R^{T} M R+M_{b}
\end{array}\right]\left\{\ddot{U}_{g}\right\}
\end{aligned}
$$

Eq. (3) can be solved using Newmark Beta unconditionally stable constant average acceleration method (see [47-51] ( $M, C$, and $K$ matrices of the benchmark building) for more information).

\section{Different parts of the MRE seismic isolator}

Different parts of the MRE isolator are shown in Figure 2.

The MRE isolator consists of some multilayered thin MRE sheets bonded to multilayered thin steel plates. The layers of the MRE sheets and replacement of steel plates among the MRE sheets make it possible

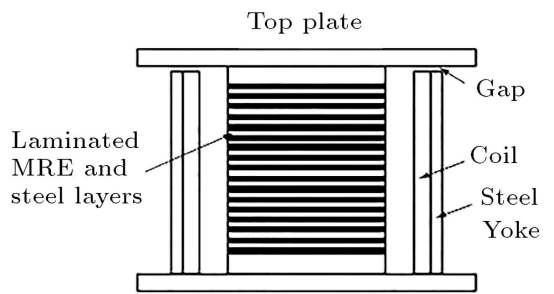

Figure 2. The cross-section of the Magnetorheological Elastomer (MRE) base isolator [46]. to avoid radial deformation of the isolator to the outside; thus, the axial pressure capacity increases and slight lateral stiffness is created in the isolator. MRE sheets and steel plates are inside the solenoid, which generates the magnetic field by applying the electric current. Solenoid is made of an electromagnetic coil and thin non-magnetic supports. The non-magnetic thin plates at the top and bottom of the solenoid are made of epoxy material. The coil is attached to the support. The spaces among the MRE sheets and the coil are determined by the maximum allowable shear strain of the MRE isolator. Due to the low conductivity of MRE materials, especially when they are used with thin MRE sheets, it is difficult to obtain MRE sheets within magnetic saturation. Replacing MRE sheets and steel plates can increase the conductivity of the isolator. Steel yoke is used to increase the magnetic field of the MRE isolator. To create the isolator movement capability, a small gap is placed between the top plate and the steel yoke (see [52] for more information).

\section{Modeling of a novel adaptive MRE base isolator}

The models used for MRE isolators should be able to capture strain stiffening in force displacement loops and take into account the nonlinear relationship between force and velocity. As mentioned in the Introduction section, several non-parametric and parametric models have been developed to describe the performances of MREs [42-46]. This study employs the novel model proposed by yang et al. [46], as shown in Figure 3. Mathematical equations are given in Eqs. (4) and (5) $[46]$ :

$$
\begin{aligned}
& F=\alpha K_{0} U+(1-\alpha) K_{0} Z+C_{0} \dot{U}, \\
& \dot{Z}=A \dot{U}-\beta|\dot{U}||Z|^{n-1} Z-\gamma \dot{U}|Z|^{n} .
\end{aligned}
$$

This model includes a Bouc-Wen component in parallel with a Viogt element. The former is utilized to reproduce hysteresis loops and the latter describes

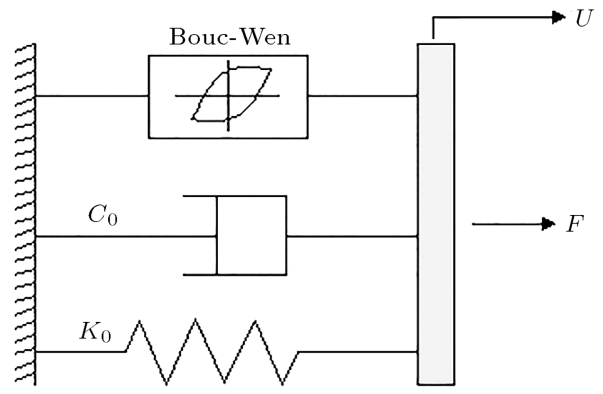

Figure 3. The suggested model for the Magnetorheological Elastomer (MRE) isolator [46]. 
solid-material behaviors. The evolutionary variable $Z$, denoting a function of time history displacement, describes the Bouc-Wen component, illustrating a large class of hysteretic behavior. In terms of mathematics, since this component is easy to use, it is extensively utilized in structural engineering and defining MR behavior.

In Eqs. (4) and (5), the spring stiffness and viscosity coefficient of this model are denoted by $K_{0}$ and $C_{0}$, respectively. $C_{0}$ represents the damping capacity of the system and $C_{0} \dot{U}$ is a component of the total force. The rest of the total force indicates the restoring force which is equal to the summation of a linear component $\alpha K_{0} U$ and a purely hysteretic component $(1-\alpha) K_{0} Z$. It should be noted that $\alpha \in(0,1)$ is the linearity level of the hysteresis loops [46].

In these relations, $A, n, \beta$, and $\gamma$ are nondimensional parameters applied to introduce the shape and size of the hysteresis loops. The parameter $A$ affects the maximum force and the parameter $n$ controls the transition from linear to nonlinear range. The parameter $n$, in this study, is assumed to be 1 , and $\beta$ and $\gamma$ form the hysteresis loops. As observed, the parameters $A, \alpha, K_{0}$, and $C_{0}$ seem to vary linearly with the current and the parameters $\beta$ and $\gamma$ are constant values for which the optimum values for parameters are proposed in [48]. Therefore, the following equations can be derived [46]:

$$
\begin{aligned}
& A=A_{\alpha}+A_{b} I, \\
& \alpha=\alpha_{\alpha}+\alpha_{b} I, \\
& K_{0}=K_{0 \alpha}+K_{0 b} I,
\end{aligned}
$$

$$
C_{0}=C_{0 \alpha}+C_{0 b} I \text {. }
$$

In Table 2, the optimum values for the parameters $A_{\alpha}, A_{b}, \alpha_{\alpha}, \alpha_{b}, K_{0 \alpha}, K_{0 b}, C_{0 \alpha}, C_{0 b}, \beta, \gamma$ are listed [46].

The maximum relative error corresponding to the introduced model and experimentally measured isolator force is less than 8\% [46]. Figure 4 shows the relationships among the isolator force time history, force displacement, and force velocity under sinusoidal load with a frequency of $4 \mathrm{~Hz}$ and an amplitude of $4 \mathrm{~mm}$.

In this study, the MRE isolator is used in modeling the base-isolated benchmark buildings. Since the base-isolated benchmark building is three-dimensional, bilateral interaction effects should be considered in the isolator behavior. The isolator forces produced by the MRE isolator in $x$ and $y$ directions can be expressed as follows:

$$
\begin{aligned}
& F_{x}=\alpha K_{0} U_{x}+(1-\alpha) K_{0} Z_{x}+C_{0} \dot{U}_{x}, \\
& F_{y}=\alpha K_{0} U_{y}+(1-\alpha) K_{0} Z_{y}+C_{0} \dot{U}_{y} .
\end{aligned}
$$

The evolutionary variable $Z$ can be achieved through the following equations [53]:

$$
\begin{aligned}
\dot{z}_{x}= & A \dot{U}_{x}-z_{x}\left(\beta\left|\dot{U}_{x} z_{x}\right|+\gamma \dot{U}_{x} z_{x}+\beta\left|\dot{U}_{y} z_{y}\right|\right. \\
& \left.+\gamma \dot{U}_{y} z_{y}\right) \times\left(z_{x}^{2}+z_{y}^{2}\right)^{\frac{n-2}{2}}, \\
\dot{z}_{y}= & A \dot{U}_{y}-z_{y}\left(\beta\left|\dot{U}_{x} z_{x}\right|+\gamma \dot{U}_{x} z_{x}+\beta\left|\dot{U}_{y} z_{y}\right|\right. \\
& \left.+\gamma \dot{U}_{y} z_{y}\right) \times\left(z_{x}^{2}+z_{y}^{2}\right)^{\frac{n-2}{2}} .
\end{aligned}
$$

Figure 5 shows the three-dimensional resultant force

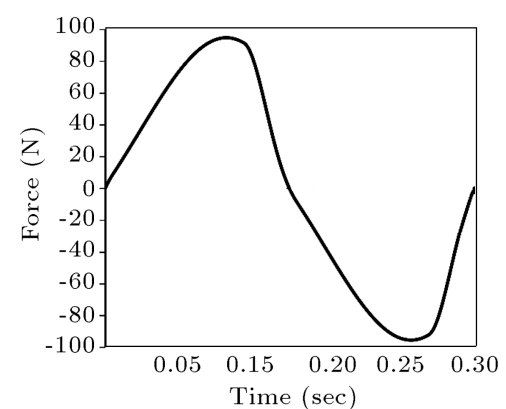

(a) Force vs. time

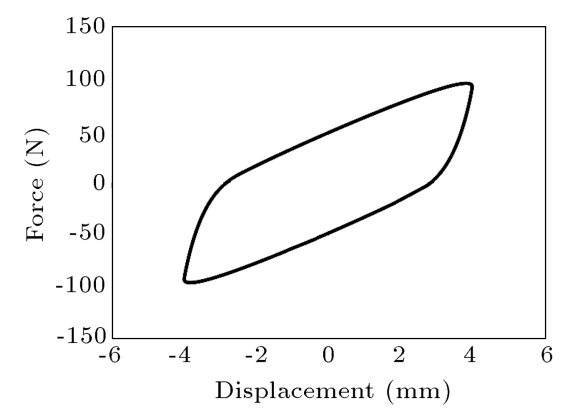

(b) Force vs. displacement

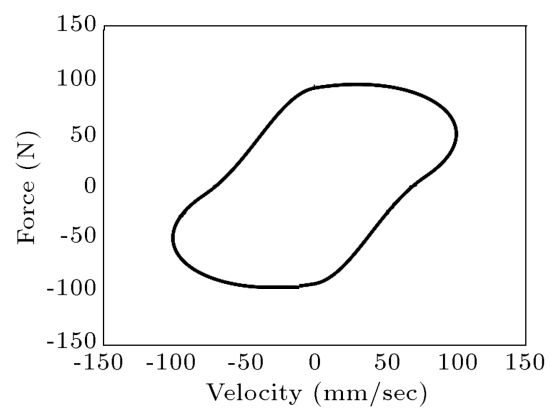

(c) Force vs. velocity

Figure 4. The responses of the model under sinusoidal load with the frequency of $4 \mathrm{~Hz}$ and amplitude of $4 \mathrm{~mm}$.

Table 2. The optimum values of the parameters of the Magnetorheological Elastomer (MRE) isolator [46].

\begin{tabular}{cccc}
\hline Parameter & Value & Parameter & Value \\
\hline$A_{\alpha}$ & 0.80225 & $A_{b}$ & $1.5043 \mathrm{I}^{-1}$ \\
$a_{\alpha}$ & 0.15371 & $a_{b}$ & $0.2893 \mathrm{I}^{-1}$ \\
$K_{0 \alpha}$ & $1.3103 /(\mathrm{N} / \mathrm{mm})$ & $K_{0 b}$ & $3.322 / \mathrm{N}^{*} \mathrm{I} / \mathrm{mm}$ \\
$C_{0 \alpha}$ & $0.044604 /\left(\mathrm{N}^{*} \mathrm{sec} / \mathrm{mm}\right)$ & $C_{0 b}$ & $0.087104\left(\mathrm{~N}^{*} \mathrm{sec}^{*} \mathrm{I} / \mathrm{mm}\right)$ \\
$\beta$ & 0.8549 & $\gamma$ & -0.91404 \\
\hline
\end{tabular}




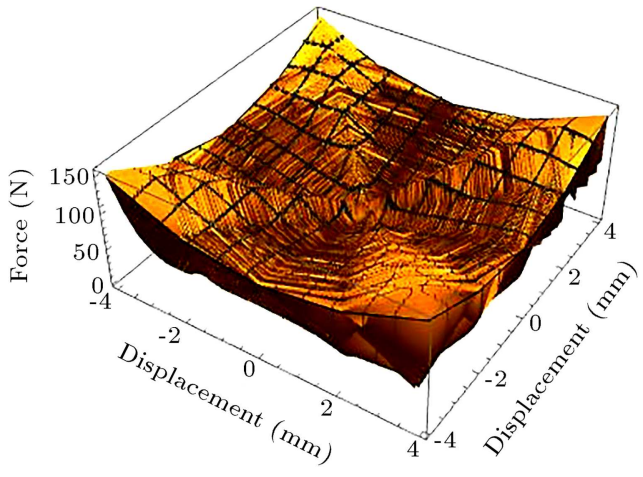

(a)

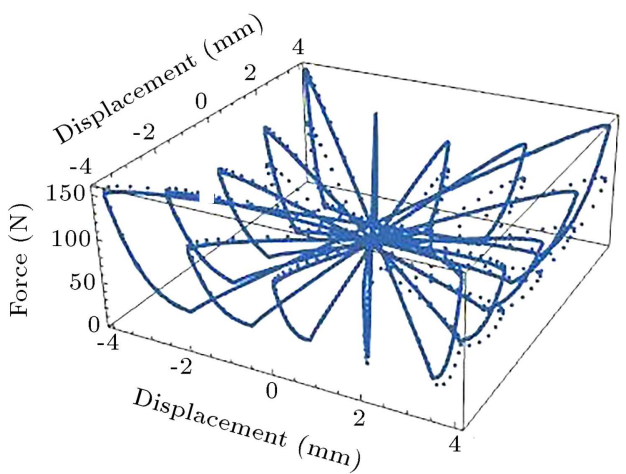

(b)

Figure 5. Three-dimensional resultant force displacement behavior.

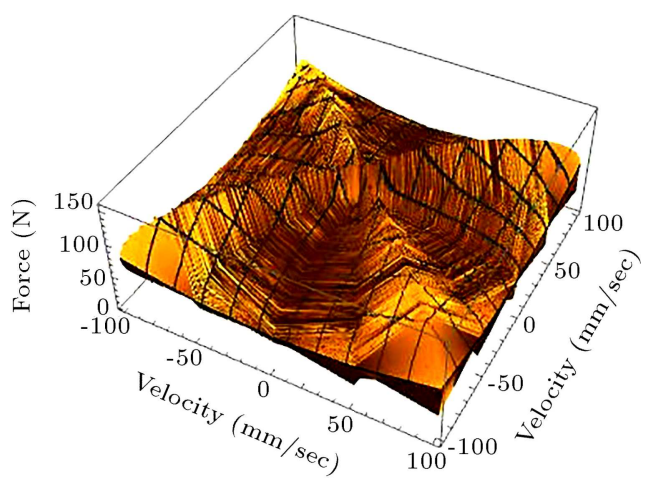

(a)

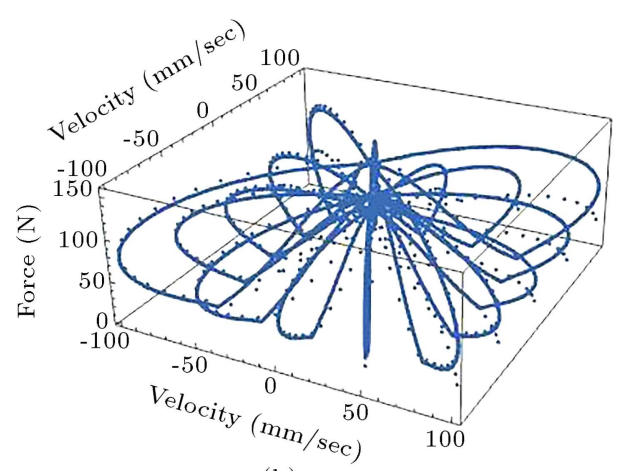

(b)

Figure 6. Three-dimensional resultant force velocity behavior.

displacement. Figure 6 presents the three-dimensional resultant force velocity under sinusoidal load with a frequency of $4 \mathrm{~Hz}$ and an amplitude of $4 \mathrm{~mm}$.

The MRE base isolator is employed in modeling the benchmark buildings. To this end, the damping and stiffness parameters in Table 2 should be adjusted so that the isolator will be capable to control the benchmark building. Of note, these two parameters affect the isolator force. In this study, the values selected for these parameters make the maximum isolator force equal to the maximum MR damper force in the base-isolated benchmark building. In Figure 7, the force displacement and force velocity relationships corresponding to the seismic isolator are illustrated for the current of $1 \mathrm{~A}$, sinusoidal signal, and various values of damping and stiffness. Given that $\frac{K_{0 b}}{K_{0 a}}, \frac{C_{0 b}}{C_{0 a}}$, the stiffness, and damping ratios are the same for the proposed model according to the selected values of stiffness and damping in [46].

In Figure 8, the relationships between the forcedisplacement and force velocity corresponding to the seismic isolator and MR damper, respectively, are presented for the current of $1 \mathrm{~A}$ and sinusoidal excitation with a frequency of $1 \mathrm{HZ}$ and an amplitude of $0.5 \mathrm{~m}$.

The maximum isolator force is equal to the maximum MR damper force in the base-isolated benchmark building. Table 3 shows the parameters used for the MRE isolator in this study.

\section{Comparison of the MR damper and MRE isolator}

The main objective of this study is to investigate the MRE isolator behavior in the base-isolated benchmark

Table 3. The parameters of the Magnetorheological Elastomer (MRE) isolator utilized in this study.

\begin{tabular}{cccc}
\hline Parameter & Value & Parameter & Value \\
\hline$A_{\alpha}$ & 0.80225 & $A_{b}$ & 1.5013 \\
$a_{\alpha}$ & 0.15371 & $a_{b}$ & 0.28939 \\
$K_{0 \alpha}$ & $249.1 \mathrm{KN} / \mathrm{m}$ & $K_{0 b}$ & $631.543 \mathrm{KN} / \mathrm{m}$ \\
$C_{0 \alpha}$ & $8.48 \mathrm{KN}^{*} \mathrm{sec} / \mathrm{m}$ & $C_{0 b}$ & $16.56 \mathrm{KN}{ }^{*} \mathrm{sec} / \mathrm{m}$ \\
$\beta$ & $4.9161 / \mathrm{m}$ & $\gamma$ & $-5.2561 / \mathrm{m}$ \\
\hline
\end{tabular}




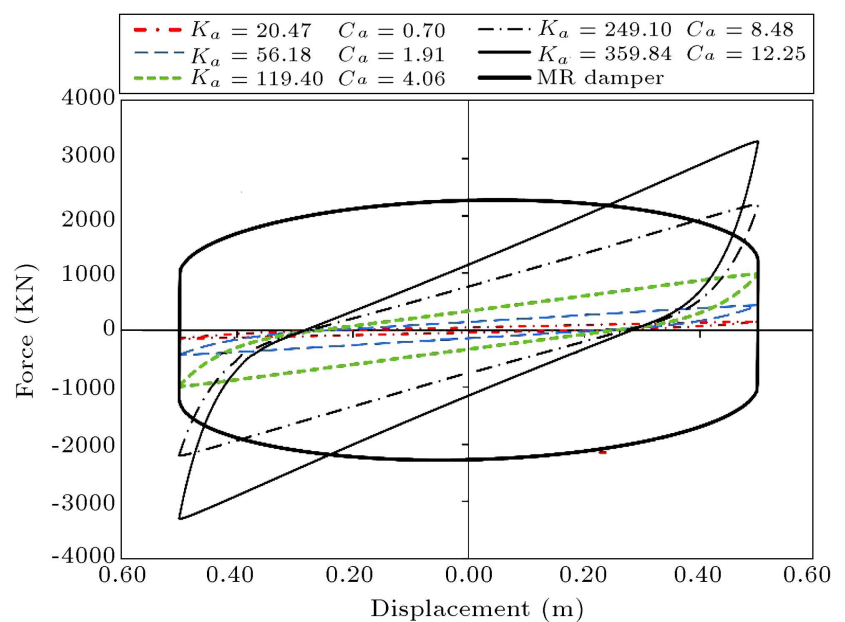

(a)

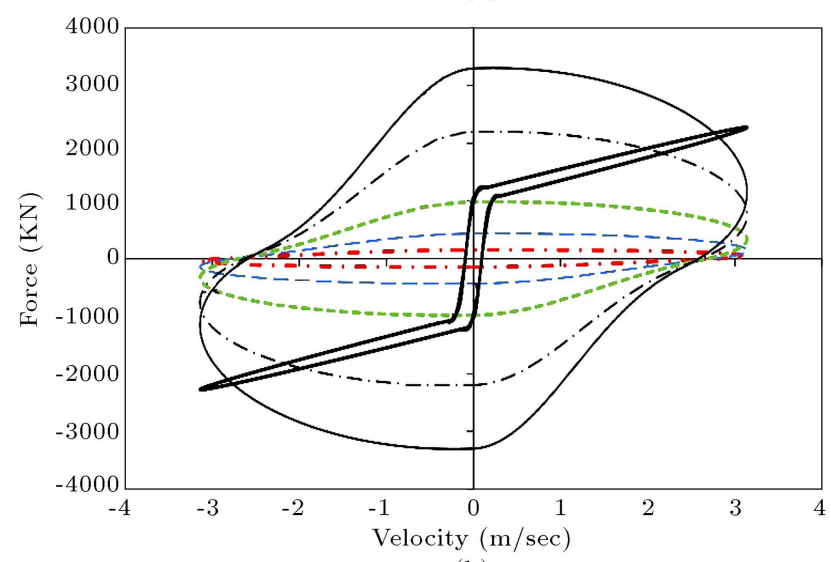

(b)

Figure 7. Comparison of force displacement and force velocity relationships for the Magnetorheological Elastomer (MRE) isolator.

building. In addition, of interest is to compare the effects of the MRE isolator and MR damper on structural responses. This section compares the behaviors of the MRE isolator and MR damper.

Several parametric mechanical models have been proposed to describe the non-linear behavior of MR

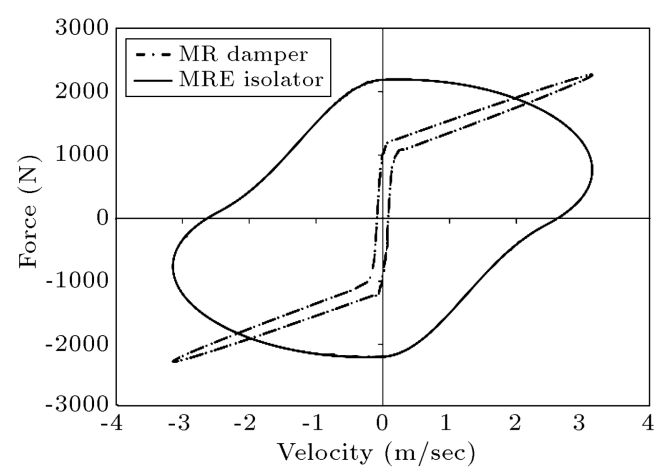

(a)

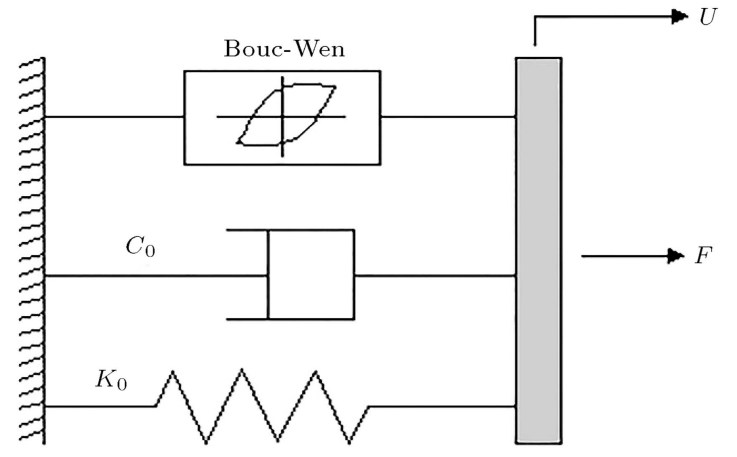

Figure 9. The simple Bouc-Wen model of the Magnetorheological (MR) damper [54].

dampers [54,55]. The most famous model that suitably predicts MR damper behavior is the smooth Bouc-Wen model used to simulate MR dampers for the semiactive control system [56,57]. Figure 9 presents the simple Bouce-Wen model for MR dampers that include a spring, dash pot, and hysteretic element in parallel.

The force generated by the damper is given by Spencer et al. [54]:

$$
F=\alpha Z f(\nu)+C_{0} \dot{U}+K_{0} U
$$

where $\alpha$ is the Bouc-Wen model parameter related to the yield stress of MR material; $K_{0}$ and $C_{0}$ are spring stiffness and dashpot damping coefficient, respectively; $U$ and $\dot{U}$ are displacement and velocity, respectively; $f(\nu)$ is a function of voltage $\nu$; and $Z$ is the hysteretic deformation of the model defined in the following equation:

$$
Y \dot{Z}=\dot{U}-\beta|\dot{U}| Z|Z|-\gamma \dot{U} Z^{2},
$$

where $Y$ is the yield displacement of the hysteretic element and $\gamma, \beta$, the Bouc-Wen model parameter. To obtain the optimal performance of a control system equipped with MR dampers, the voltage applied to the current driver must vary according to the measured

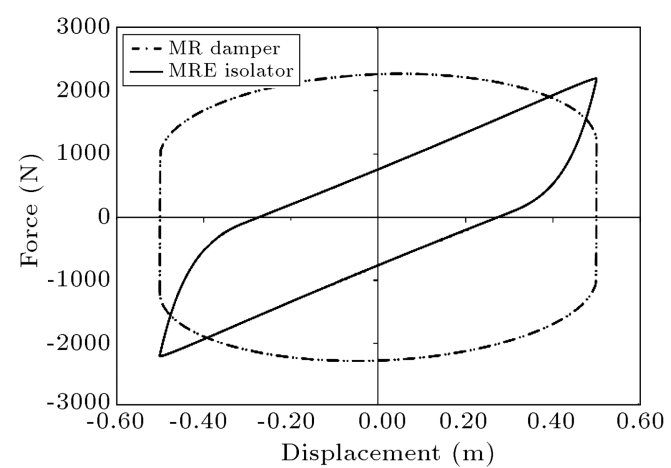

(b)

Figure 8. Comparison of force displacement and force velocity relationships for the Magnetorheological Elastomer (MRE) isolator and Magnetorheological (MR) damper. 
feedback at any moment to change the damping force. Thus, for accounting this accordance, the coefficient $\alpha$ and damping coefficient $C_{0}$ in Eq. (9) are defined as a linear function of the efficient voltage, as given by the following equations $[56,57]$.

$$
\alpha=\alpha_{\alpha}+\alpha_{b} I, \quad C_{0}=C_{0 \alpha}+C_{0 b} I
$$

Since the linear viscoelastic region of the MR damper is too small, the yield displacement of the MR damper is consequently quite small. In other words, the MR damper operates in the post-yield region. Table 4 shows the parameters utilized in the MR damper in the base-isolated benchmark building.

According to Figures 10 and 11, the relationships between the force displacement and force velocity of the MRE isolator and MR damper are presented for the current of $1 \mathrm{~A}$ and sinusoidal excitation with different frequencies and amplitudes of $0.5 \mathrm{~m}$. It can be observed that the loading frequency has no effect on the maximum force of the MRE isolator and is more effective in the maximum force of the MR damper.

In Figures 12 and 13, the relationships between force displacement and force velocity of the MRE isolator and MR damper are respectively shown for various currents and sinusoidal excitation with a frequency of $1 \mathrm{HZ}$ and an amplitude of $0.5 \mathrm{~m}$. Obviously, intensifying the current increases the slope of the force displacement curve and the surrounding area of the force displacement curve of the MRE isolator. Note that the slope and area of the curve are directly related to the stiffness and damping, respectively. Therefore, the MRE isolator exhibits variable stiffness and damping properties. Moreover, intensifying the

Table 4. The parameters of the Magnetorheological (MR) damper utilized in the benchmark base isolation building [47].

\begin{tabular}{cccc}
\hline Parameter & Value & Parameter & Value \\
\hline Yield displacement & $0.001637 \mathrm{~m}$ & $\mathrm{~K}$ & $205.774 \mathrm{KN} / \mathrm{m}$ \\
$C_{0 \alpha}$ & $90.5 \mathrm{KN} / \mathrm{sec} / \mathrm{m}$ & $C_{0 b}$ & $73 \mathrm{KN}^{*} \mathrm{sec} / \mathrm{m}$ \\
$C_{\alpha}$ & 66.72 & $\alpha_{b}$ & 258 \\
$\beta$ & 0.50 & $\gamma$ & 0.50 \\
\hline
\end{tabular}

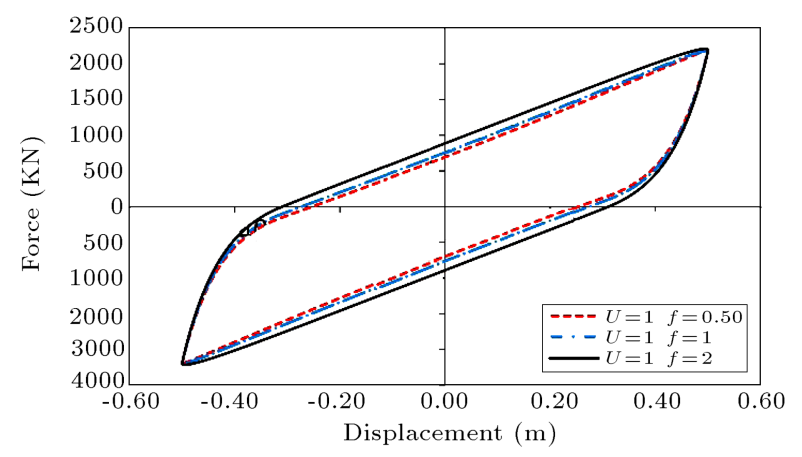

(a)

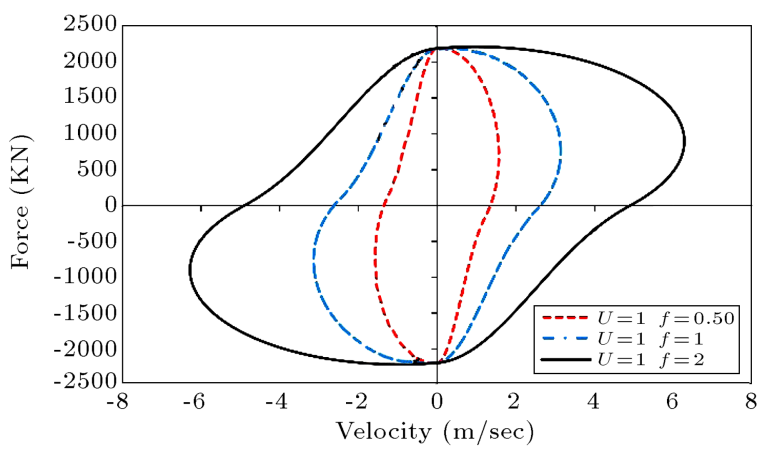

(b)

Figure 10. Force displacement and force velocity relationships for the Magnetorheological Elastomer (MRE) isolator with different frequencies.

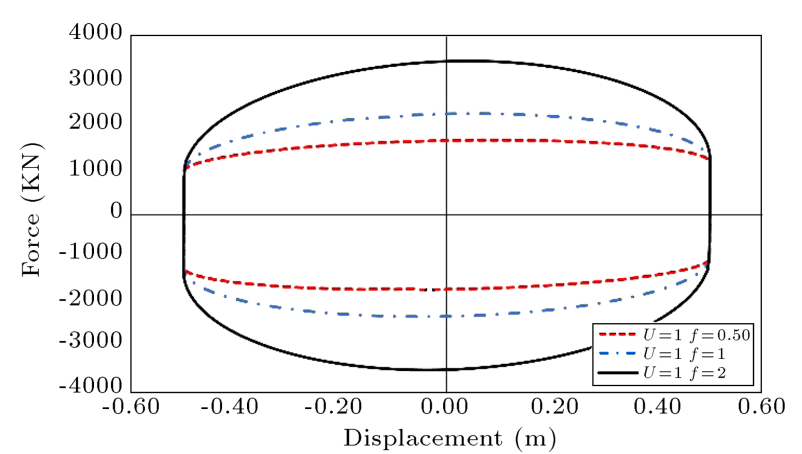

(a)

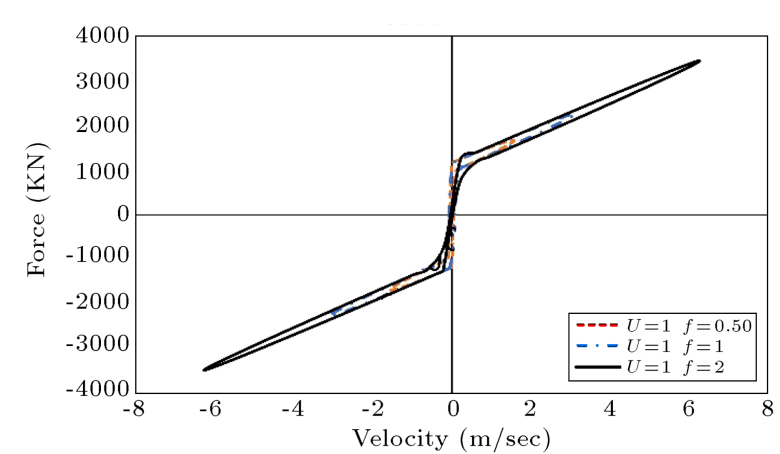

(b)

Figure 11. Force displacement and force velocity relationships for the Magnetorheological (MR) damper with different frequencies. 


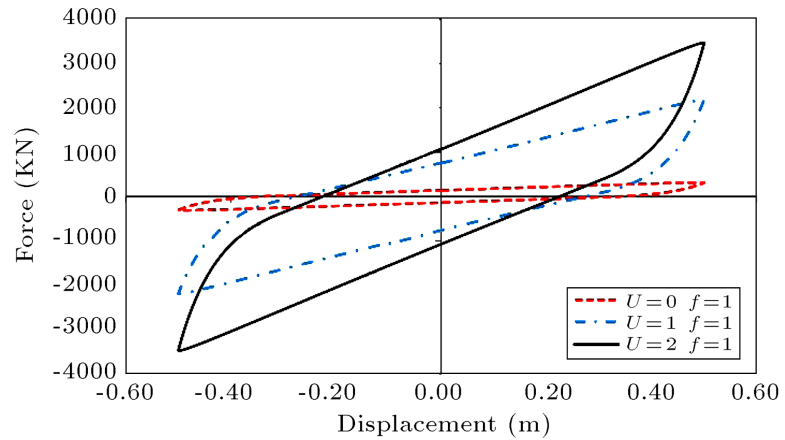

(a)

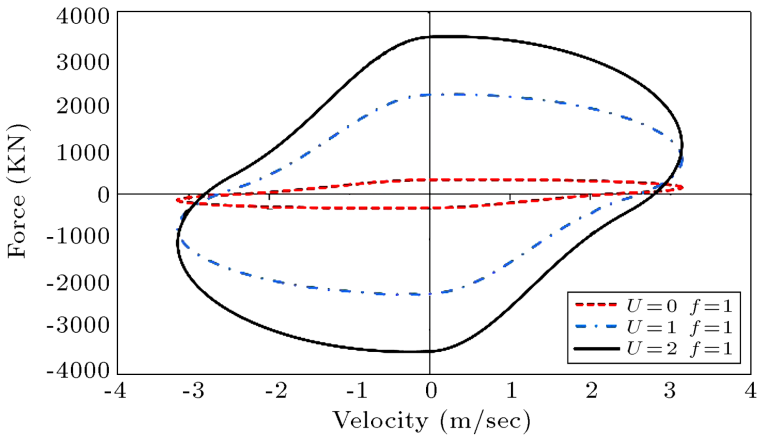

(b)

Figure 12. The force displacement and force velocity relationships for the Magnetorheological Elastomer (MRE) isolator with different currents.

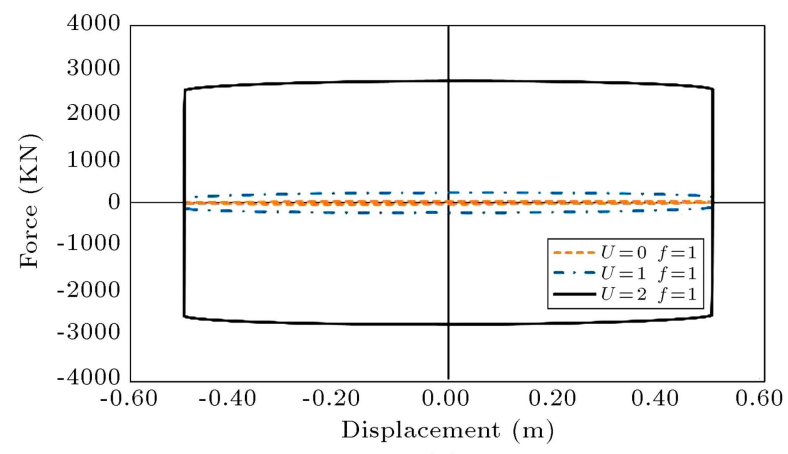

(a)

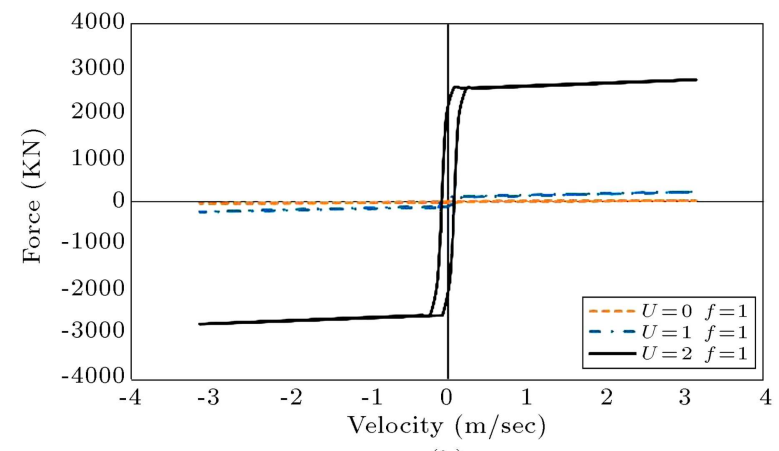

(b)

Figure 13. The force displacement and force velocity relationships for the Magnetorheological (MR) damper with different currents.

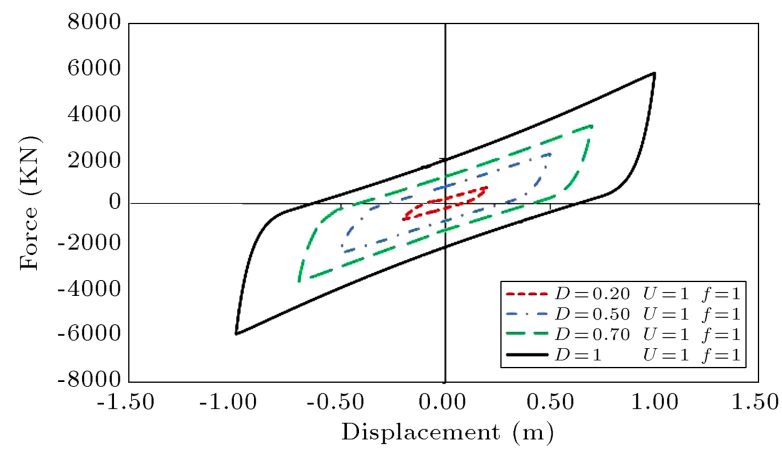

(a)

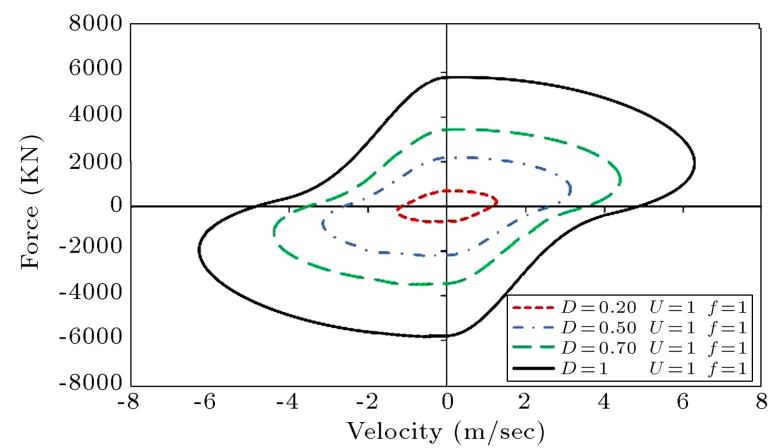

(b)

Figure 14. Force displacement and force velocity relationships for the Magnetorheological Elastomer (MRE) isolator with different amplitudes.

current increases the surrounding area of the force displacement curve of the MR damper, but does not change the slope of the curve. In other words, as the current intensifies, the damping of the MR damper increases, but its stiffness does not change.

In Figures 14 and 15, the relationships between the force displacement and force velocity of the seismic isolator and MR damper are respectively presented for the current of $1 \mathrm{~A}$, sinusoidal excitation with a frequency of $1 \mathrm{HZ}$, and different amplitudes. Although the behavior of the MRE isolator is linear in small displacements and nonlinear in large displacements, the behavior of the MR damper is nonlinear in all displacements. It should be added that more energy can be absorbed when the system shows a nonlinear behavior. Therefore, it can be concluded that:

1. The stiffness of the MRE isolator and yield stress of the MR damper depend on the field. In other words, the strengths of the MRE isolator and MR damper are determined by the dependence of both stiffness and yield stress in the field, respectively;

2. The MRE isolator acts with linear viscoelastic properties when the displacement is negligible. In- 


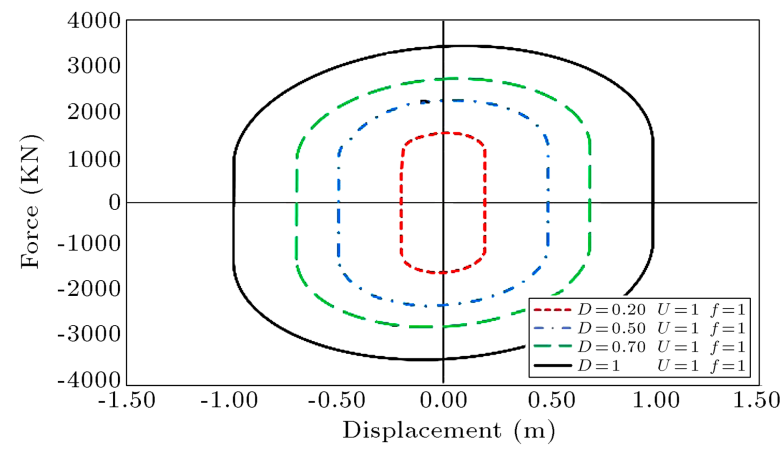

(a)

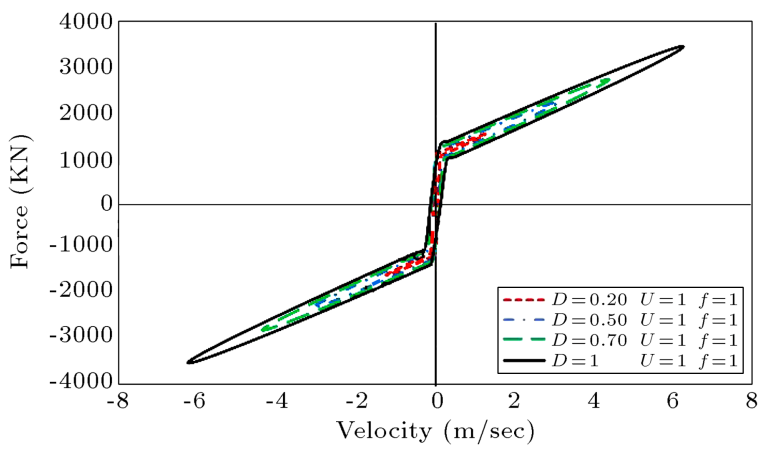

(b)

Figure 15. Force displacement and force velocity relationships for the Magnetorheological (MR) damper with different amplitudes.

creasing the range of displacement stimulates the nonlinear behavior of the MRE isolator. The linear viscoelastic region of the MR damper lies within a negligible range of displacements. Therefore, the MR damper always behaves nonlinearly. In other words, the MRE isolator generally operates in the pre-yield region, and an increase in displacement occurs in the post-yield region, while the MR damper operates in the post-yield region;

3. The MRE isolator has controllable mechanical properties. In other words, the MRE damper exhibits variable stiffness and damping properties, while the MR damper exhibits damping controllable properties.

\section{Numerical result}

In this study, the base-isolated benchmark building is used to study the MRE isolator behavior. A threedimensional model of the base-isolated benchmark building was developed by Narasimhan and Nagarajajah in 2004. In order to examine the effect of far-field and near-field earthquakes, according to the Iranian code of practice for seismic-resistant design of buildings (Standard no. 2800), three far-field and three nearfield earthquakes were investigated. Earthquakes were scaled to the acceleration $0.5 \mathrm{~g}$. Far-field and nearfield earthquakes were selected based on the distance to surface rupture and ground velocity amplitude. According to the research conducted by Jangid and Kelly [58], near-fault pulse-like motion can be associated with ground velocity amplitudes of approximately $50 \mathrm{~cm} / \mathrm{s}$ or greater. Thus, it can be concluded that the ground velocities below approximately $30 \mathrm{~cm} / \mathrm{s}$ would not be associated with near-field motion [5860]. The earthquakes considered in this study are the Bam, Manjil, and Tabas earthquakes as near-field earthquakes, and the Loma Prieta, San Fernando, and Boshruyeh earthquakes as far-field earthquakes. These earthquakes were simultaneously applied in two hori- zontal directions. Each of these earthquakes has two components called Fault Parallel (FP) and Fault Normal $(\mathrm{FN})$. The components were placed in the northsouth and east-west directions. Vertical earthquakes were not considered in the dynamic analysis of the base-isolated benchmark building. The specifications of the earthquakes are shown in Table 5, in which TP is the period pulse of the earthquakes and Rrup is the distance from the rupture surface.

Structural responses under study include:

$J 1 \quad$ Peak base shear of the base-isolated benchmark building (KN)

J2 Peak story shear of the base-isolated benchmark building (KN)

J3 Peak base displacement of the base-isolated benchmark building ( $\mathrm{m}$ )

J4 Peak story drift of the base-isolated benchmark building $(\mathrm{m})$

J5 Peak absolute acceleration of the base-isolated benchmark building $\left(\mathrm{m} / \mathrm{s}^{2}\right)$

J6 Root Mean Square (RMS) base displacement of the base-isolated benchmark building $(\mathrm{m})$

J7 Root Mean Square (RMS) absolute acceleration of the base-isolated benchmark building $\left(\mathrm{m} / \mathrm{s}^{2}\right)$

Figure 16 shows the earthquakes applied in the two directions of FN and FP. Figure 17 shows the acceleration spectrum of the earthquake records. Figure 18 shows the Fourier spectrum of the earthquake records.

Equipping the structure with a seismic isolation system increases the structure lifetime, but reduces the acceleration imposed on the structure. Longperiod pulses are observed in earthquakes such as Bam and Manjil and they increase the acceleration of the structure using the seismic isolation system. The seismic isolation system in such situations shows a poor 
Table 5. Specifications of the earthquakes used in this study.

\begin{tabular}{|c|c|c|c|c|c|c|c|c|c|}
\hline Earthquake & Station & Magnitude & $\begin{array}{c}\mathrm{TP} \\
(\mathrm{sec})\end{array}$ & $\begin{array}{l}\text { Rrup } \\
(\mathrm{km})\end{array}$ & $\begin{array}{c}\text { Predominant } \\
\text { frequency } \\
(\mathrm{HZ})\end{array}$ & Direction & $\begin{array}{l}\text { PGD } \\
(\mathrm{cm})\end{array}$ & $\begin{array}{c}\text { PGV } \\
(\mathrm{cm} / \mathrm{sec})\end{array}$ & $\begin{array}{c}\text { PGA } \\
(\mathrm{g})\end{array}$ \\
\hline \multirow[t]{2}{*}{ Bam } & \multirow[t]{2}{*}{ Bam } & \multirow[t]{2}{*}{ 6.6 MW } & \multirow[t]{2}{*}{2.023} & \multirow[t]{2}{*}{1.70} & 0.61 & F-P & 34.12 & 124.11 & 0.81 \\
\hline & & & & & 4.52 & $\mathrm{~F}-\mathrm{N}$ & 23.20 & 60.15 & 0.63 \\
\hline \multirow[t]{2}{*}{ Manjil } & \multirow[t]{2}{*}{$\mathrm{Ab}$ Bar } & \multirow[t]{2}{*}{$7.37 \mathrm{MW}$} & \multirow[t]{2}{*}{-} & \multirow[t]{2}{*}{12.55} & 2.93 & F-P & 24.82 & 42.83 & 0.51 \\
\hline & & & & & 4.54 & F-N & 30.06 & 50.17 & 0.50 \\
\hline \multirow{2}{*}{ Tabas } & \multirow{2}{*}{ Tabas } & \multirow{2}{*}{$7.35 \mathrm{MW}$} & \multirow{2}{*}{6.19} & \multirow{2}{*}{2.05} & 1.32 & F-P & 46.34 & 99.78 & 0.85 \\
\hline & & & & & 0.22 & F-N & 97.61 & 123.05 & 0.86 \\
\hline \multirow{2}{*}{$\begin{array}{l}\text { Loma } \\
\text { Prieta }\end{array}$} & \multirow{2}{*}{$\begin{array}{c}\text { Brekeley } \\
\text { lab }\end{array}$} & \multirow{2}{*}{$6.93 \mathrm{MW}$} & \multirow{2}{*}{-} & \multirow{2}{*}{79.25} & 1.05 & F-P & 2.42 & 8.28 & 0.05 \\
\hline & & & & & 1.00 & $\mathrm{~F}-\mathrm{N}$ & 5.38 & 21.78 & 0.12 \\
\hline \multirow{2}{*}{$\begin{array}{c}\text { San } \\
\text { Fernando }\end{array}$} & \multirow{2}{*}{$\begin{array}{c}\text { San } \\
\text { Antonio dam }\end{array}$} & \multirow{2}{*}{$6.61 \mathrm{MW}$} & \multirow{2}{*}{-} & \multirow{2}{*}{61.73} & 2.42 & F-P & 0.88 & 2.86 & 0.06 \\
\hline & & & & & 2.61 & $\mathrm{~F}-\mathrm{N}$ & 0.93 & 3.75 & 0.08 \\
\hline \multirow{2}{*}{ Tabas } & \multirow{2}{*}{ Boshruyeh } & \multirow{2}{*}{$7.35 \mathrm{MW}$} & \multirow{2}{*}{-} & \multirow{2}{*}{28.79} & 1.86 & F-P & 7.65 & 13.30 & 0.11 \\
\hline & & & & & 0.22 & $\mathrm{~F}-\mathrm{N}$ & 7.84 & 15.43 & 0.08 \\
\hline
\end{tabular}

performance and may cause serious damages to the whole structure. Similar conditions are also observed in the Boshruyeh far-field earthquakes. Traditional isolation systems are usually designed in accordance to two or three times the fundamental time period of the structure. Therefore, the aforementioned problem is likely to happen. In other words, the structure may exhibit a successful performance against an earthquake while having a poor performance in another. This problem is resolved in adaptive isolators. In adaptive isolators, isolation stiffness and damping change during the earthquake.

In this study, two fuzzy controllers are implemented to specify the MRE isolator current. Figure 19 shows the schematic control system.

Earthquakes in the directions $x$ and $y$ are simultaneously applied to the structure. Sensors measure the inputs of the controllers. Each controller has two inputs, namely base displacement and roof acceleration, in the $x$ and $y$ directions. The current applied to the isolator is equal to the average of the current of the $x$ and $y$ directions. Finally, the isolator force is calculated and applied to the structure. Each input includes three Gaussian membership functions, which are shown in Figure 20. Membership functions for the output variable are shown in Figure 21, and the fuzzy rules are presented in Table 6 . The surface of the fuzzy rules is illustrated in Figure 22.

In Figure 23, the force displacement and force velocity curves of the MRE isolator are illustrated for the Tabas near-field earthquake.

Figure 24 presents the maximum relative displacements and floor accelerations for the three control cases in different earthquakes in the base-isolated benchmark buildings. These controllers include the adaptive isolator (MRE isolator), passive isolator (elastomeric isolator), and semi-active MR damper (hybrid system of the passive isolator and MR damper). The properties of the passive isolator are $K=919.422 \mathrm{KN} / \mathrm{m}$, $C=27.717 \mathrm{KN} . \mathrm{S} / \mathrm{m}$.

In all the earthquakes, except Tabas earthquake, a decrease observed in the relative displacements and

Table 6. Fuzzy inference rule.

\begin{tabular}{cccc}
\hline \multirow{2}{*}{ Acceleration } & \multicolumn{3}{c}{ Displacement } \\
\cline { 2 - 4 } & N & $\mathbf{Z}$ & $\mathbf{P}$ \\
\hline $\mathrm{N}$ & $\mathrm{PB}$ & $\mathrm{PM}$ & $\mathrm{PB}$ \\
$\mathrm{Z}$ & $\mathrm{PM}$ & $\mathrm{Z}$ & $\mathrm{PM}$ \\
$\mathrm{P}$ & $\mathrm{PB}$ & $\mathrm{PM}$ & $\mathrm{PB}$ \\
\hline
\end{tabular}




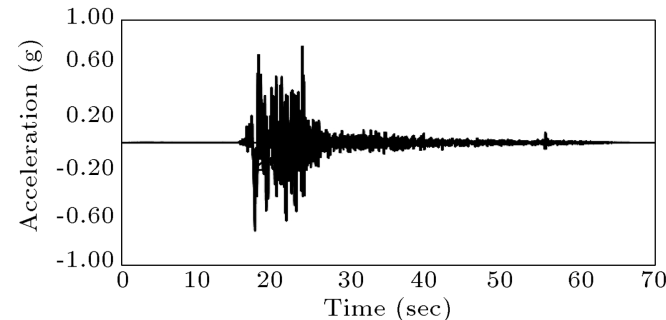

(a) Bam-FP

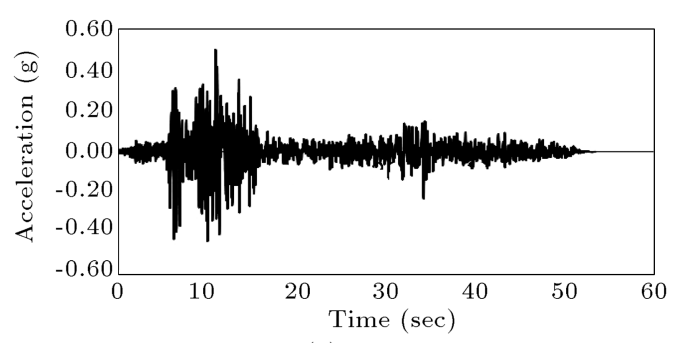

(c) Manjil-FP

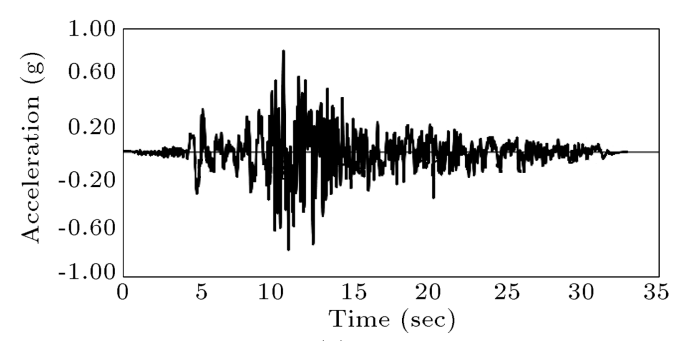

(e) Tabas-FP

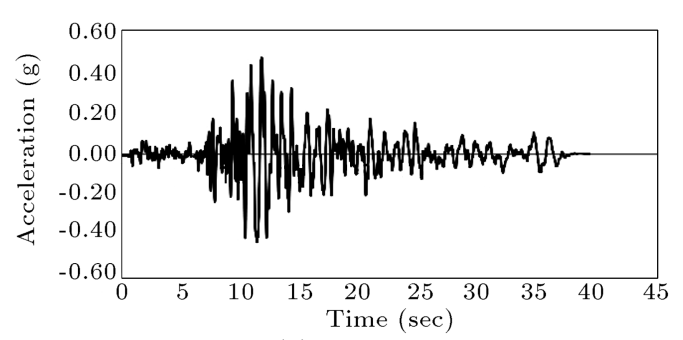

(g) Loma Prieta-FP

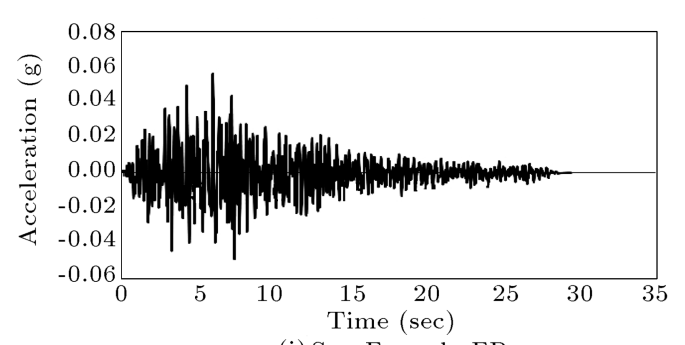

(i) San Ferando-FP

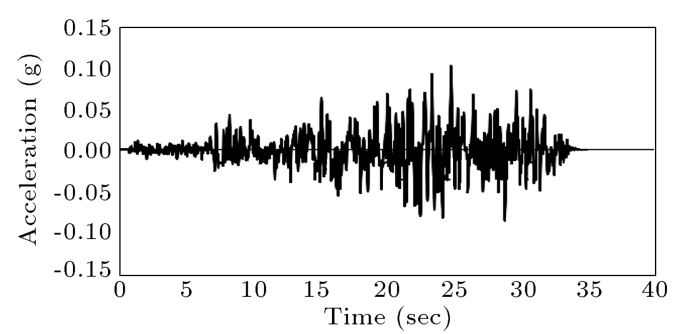

(k) Boshruyeh-FP

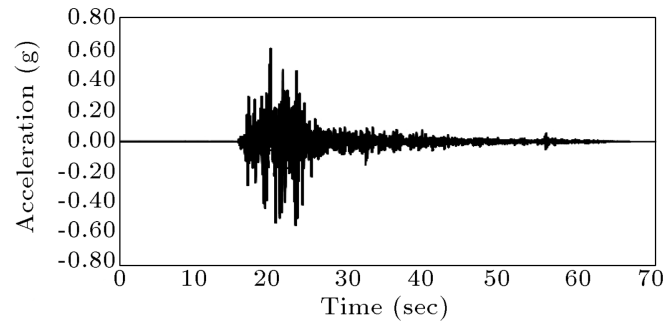

(b) Bam-FN

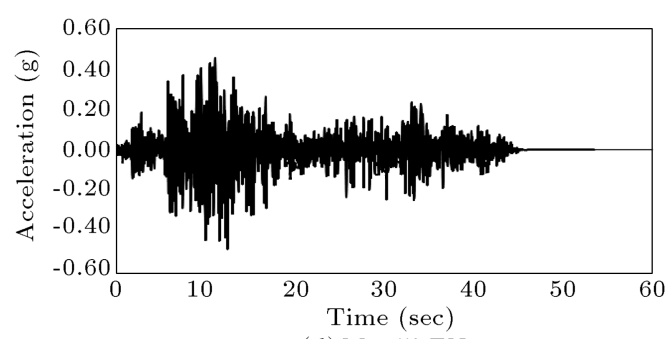

(d) Manjil-FN

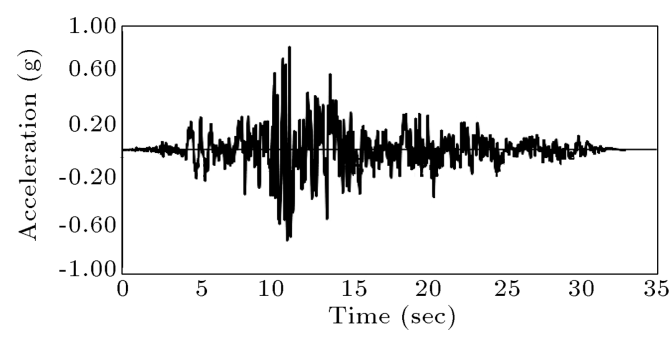

(f) Tabas-FN

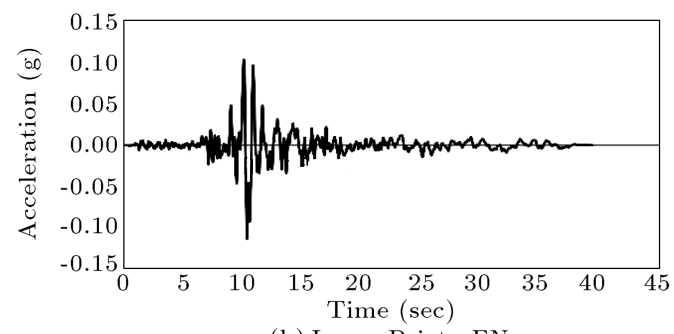

(h) Loma Prieta-FN

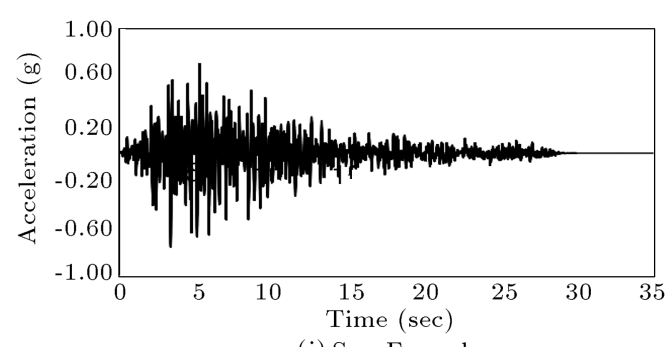

(j) San Ferando

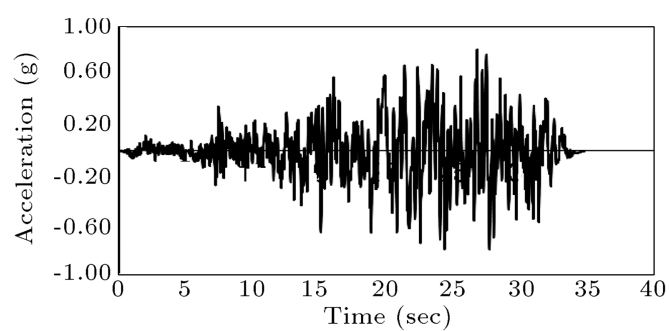

(1) Boshruyeh-FN

Figure 16. Earthquakes applied in the two directions of Fault Normal (FN) and Fault Parallel (FP). 


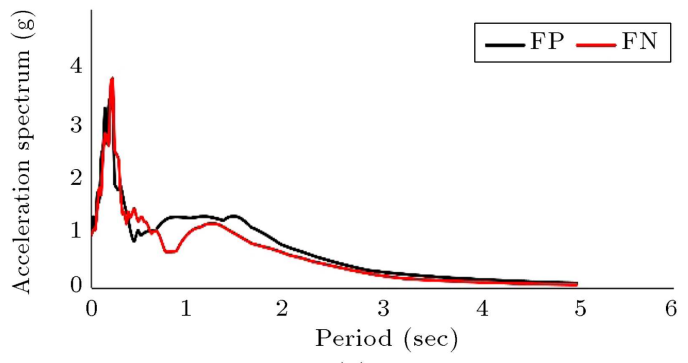

(a) Bam

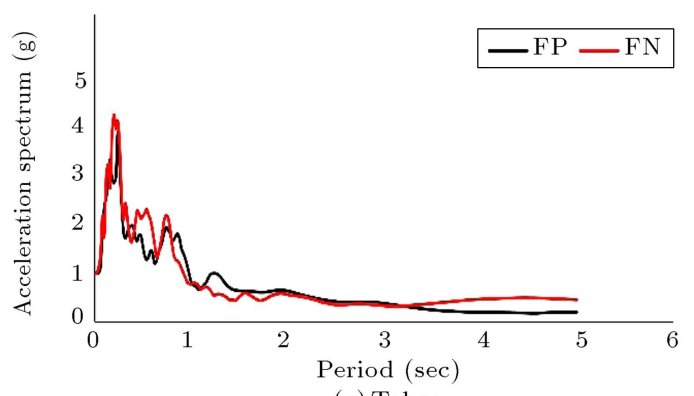

(c) Tabas

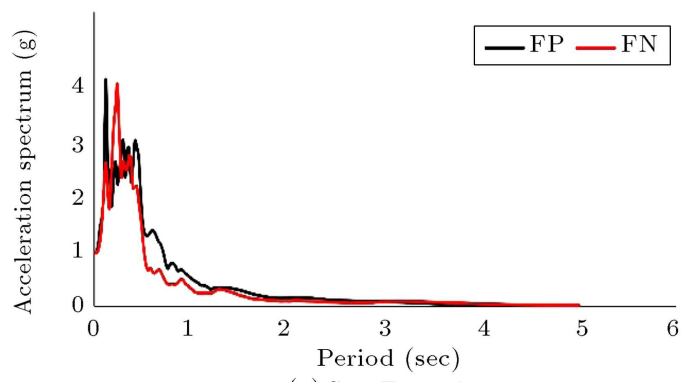

(e) San Ferando

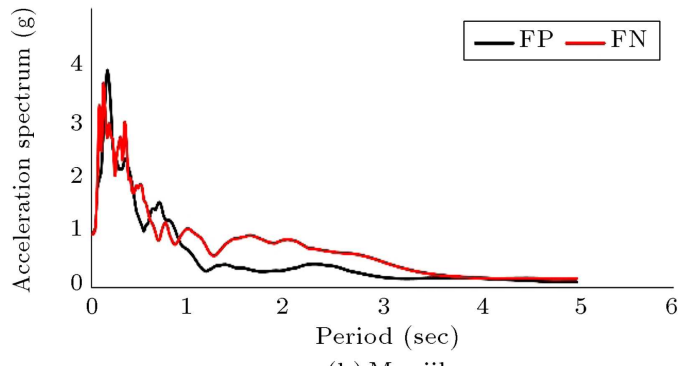

(b) Manjil

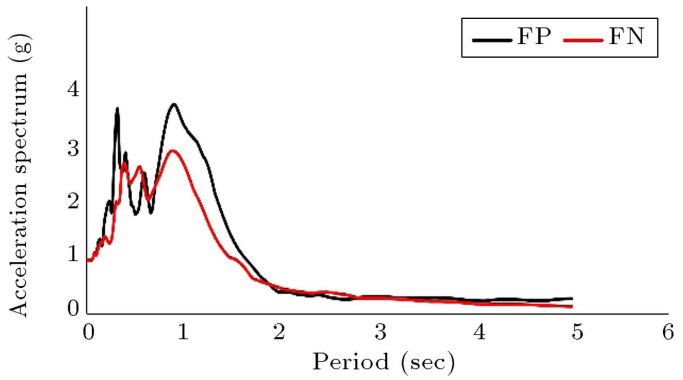

(d) Loma Prieta

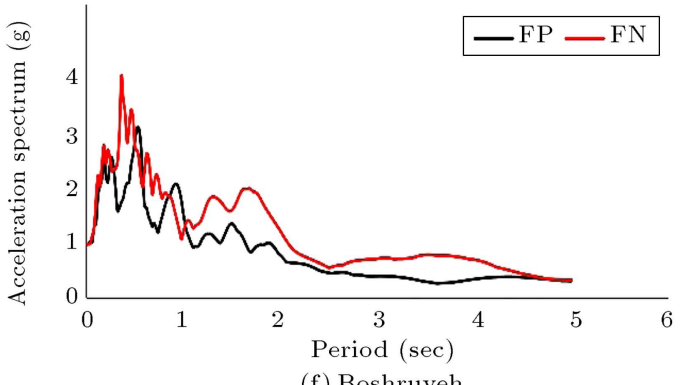

(f) Boshruyeh

Figure 17. The acceleration spectrum of the earthquake records.

floor accelerations in the adaptive isolator is greater than that in the passive isolator and hybrid system. The distribution of relative displacement and floor accelerations in the passive isolator and hybrid system in different earthquakes shows that these controllers are highly dependent on the type of earthquakes. Figures 25 and 26 indicate the time history of base displacement and roof acceleration of this building.

It was observed that the maximum base displacement in the hybrid control system was smaller than that in other two controllers; however, the maximum roof acceleration in the adaptive isolator was smaller than that in the other two controllers. The maximum base displacement of the adaptive isolator is lower than that of the passive isolator.

Maximum structural responses including base displacement, story drift, story acceleration, base shear, and story shear were calculated for comprehensive discussion of the MRE isolator behavior. Tables 7 and 8 show the maximum structural responses for different control systems. Various control systems are presented below:

Case 1: 92 elastomeric isolators (the properties of the elastomeric isolator are $K=919.422 \mathrm{KN} . \mathrm{s} / \mathrm{m}$ and $C=$ 27.717 KN.S/m);

Case 2: 92 elastomeric isolators and $16 \mathrm{MR}$ dampers (eight dampers in the $x$ direction and eight dampers in the $y$ direction) (hybrid control system);

Case 3: 92 MRE isolators (the parameters of the MRE isolator are based on Table 3 ).

In Case 2, the clipped optimal control is applied for specifying the voltage MR dampers. The parameters of the MR damper are given in Table 4. The properties of the elastomeric isolator are $K=$ $919.422 \mathrm{KN} / \mathrm{m}$ and $C=27.717 \mathrm{KN} . \mathrm{S} / \mathrm{m}$.

In Table 9, MRE isolator responses and elastomeric isolator responses are compared. In Table 10, MRE isolator responses and semi-active MR damper responses are compared.

MRE isolator in the near-field earthquake is characterized by better control than the elastomeric isolator over reducing the base displacement, story drifts, and floor accelerations. The semi-active MR damper has better control than MRE isolator over reducing base 


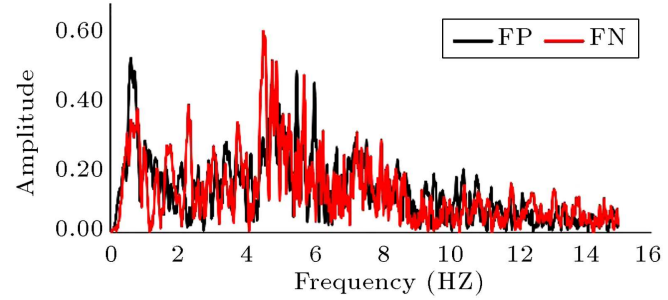

(a) Bam

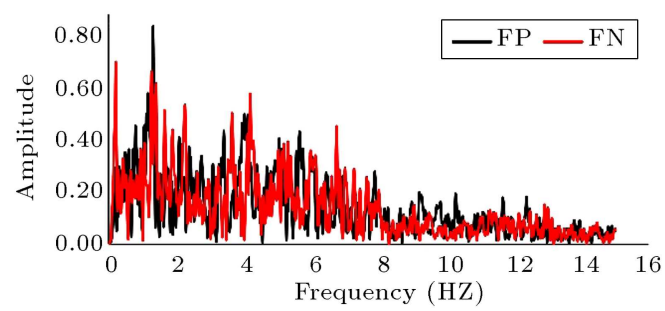

(c) Tabas

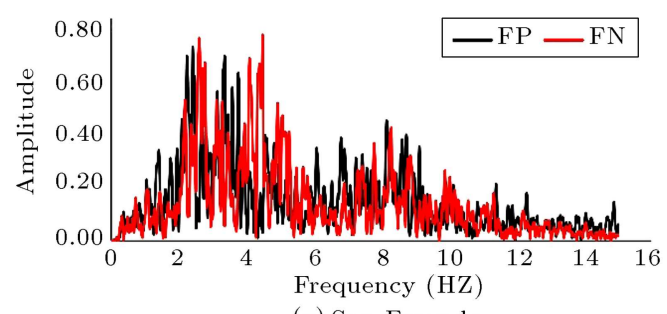

(e) San Ferando

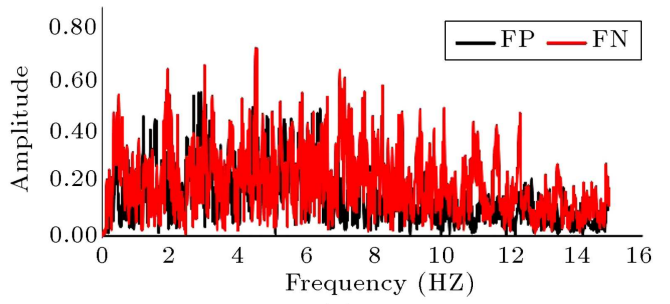

(b) Manjil

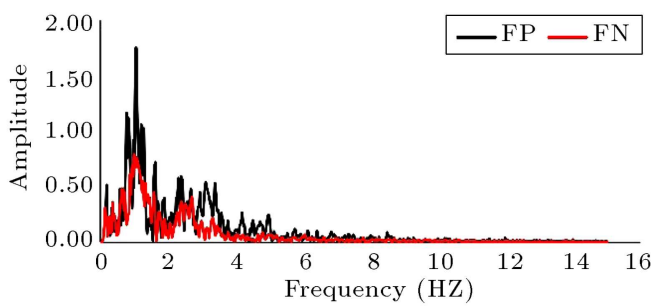

(d) Loma Prieta

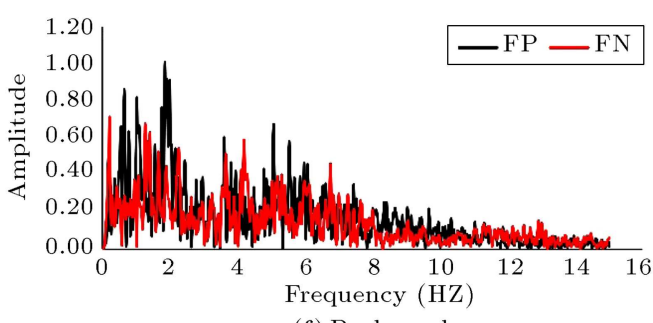

(f) Boshruyeh

Figure 18. The Fourier spectrum of the earthquake records.

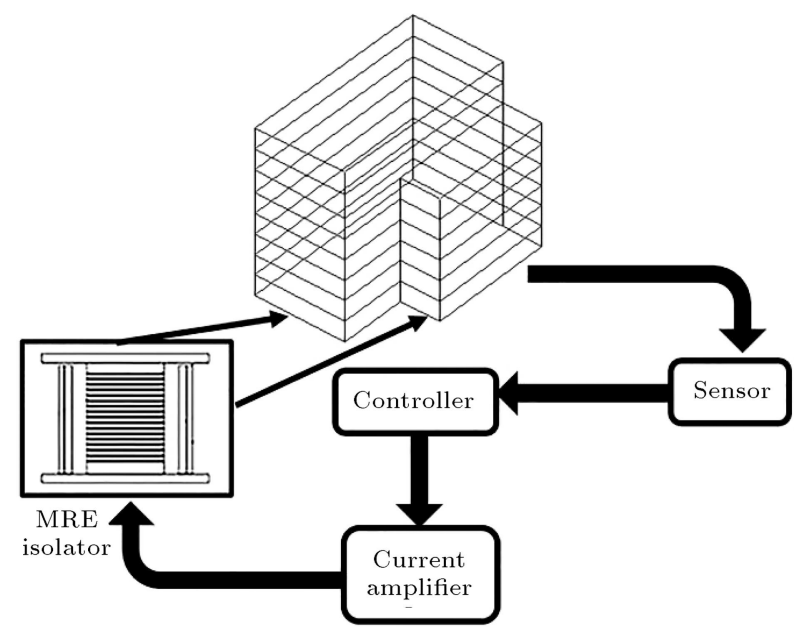

Figure 19. The schematic of the control system.

displacement; however, it causes an increase in floor accelerations and story drifts. The MRE isolator for both far-field and near-field earthquakes outperforms the semi-active MR damper in reducing story acceleration, story drift, and story shear.

\section{Conclusion}

This study investigates the performance of a new type of seismic isolator called Magnetorheological Elastomer (MRE). According to previous findings and experimental results, a mathematical model was presented for this isolator. In this study, the MRE isolator was implemented in the base-isolated benchmark building. Due to the three-dimensional structure of the base-isolated benchmark buildings, the effects of bilateral interaction were considered in the MRE isolator behavior. The parameters required to adapt the isolator analytical model to the isolator experimental model were already specified in the past researches, and the same values were determined in this study. Three control cases were considered for different earthquakes in the base-isolated benchmark building. The distribution of relative displacement and floor accelerations in the passive isolator and the semi-active MR damper in different earthquakes indicated that the these controllers were dependent on the earthquake types. Three far-field and three near-field earthquakes were investigated in this study. It was observed that all the three control systems had the utmost responses to Tabas earthquake. Given that the isolation period (the passive isolator) was 3 seconds and the predominant frequency of this earthquake was $0.22 \mathrm{HZ}$, the responses of passive isolator increased and the resonance phenomenon was witnessed. Increasing the responsiveness of the adaptive isolator in this earthquake can be 
Table 7. Maximum structural responses for different control systems for the earthquake direction FPX-FNY.

\begin{tabular}{|c|c|c|c|c|c|c|c|c|}
\hline Earthquake & Control case & J1 & J2 & J3 & J4 & J5 & J6 & J7 \\
\hline \multirow{3}{*}{ Bam } & Case 1 & 49980 & 42180 & 0.65 & 0.009 & 2.78 & 0.17 & 0.56 \\
\hline & Case 2 & 50390 & 42490 & 0.50 & 0.009 & 3.93 & 0.07 & 0.44 \\
\hline & Case 3 & 25290 & 20330 & 0.52 & 0.004 & 1.73 & 0.10 & 0.22 \\
\hline \multirow{3}{*}{ Manjil } & Case 1 & 43650 & 36910 & 0.82 & 0.01 & 2.33 & 0.27 & 0.77 \\
\hline & Case 2 & 38960 & 32820 & 0.38 & 0.01 & 2.90 & 0.09 & 0.60 \\
\hline & Case 3 & 20850 & 17050 & 0.40 & 0.004 & 1.36 & 0.16 & 0.35 \\
\hline \multirow{3}{*}{ Tabas } & Case 1 & 66820 & 56040 & 1.04 & 0.015 & 3.60 & 0.45 & 1.34 \\
\hline & Case 2 & 54080 & 46260 & 0.75 & 0.013 & 4.04 & 0.20 & 1.09 \\
\hline & Case 3 & 85220 & 72890 & 0.72 & 0.018 & 5.95 & 0.24 & 1.19 \\
\hline \multirow{3}{*}{$\begin{array}{l}\text { Loma } \\
\text { Prieta }\end{array}$} & Case 1 & 4164 & 3658 & 0.05 & 0.001 & 0.31 & 0.02 & 0.07 \\
\hline & Case 2 & 3548 & 3184 & 0.04 & 0.001 & 0.37 & 0.01 & 0.05 \\
\hline & Case 3 & 3109 & 2411 & 0.10 & 0.001 & 0.21 & 0.04 & 0.06 \\
\hline \multirow{3}{*}{$\begin{array}{c}\text { San } \\
\text { Fernando }\end{array}$} & Case 1 & 1113 & 927 & 0.02 & 0.001 & 0.06 & 0.01 & 0.02 \\
\hline & Case 2 & 2236 & 1768 & 0.001 & 0.001 & 0.43 & 0.001 & 0.06 \\
\hline & Case 3 & 651.1 & 573.2 & 0.03 & 0.001 & 0.15 & 0.02 & 0.01 \\
\hline \multirow{3}{*}{ Tabas } & Case 1 & 10150 & 8549 & 0.15 & 0.002 & 0.54 & 0.05 & 0.20 \\
\hline & Case 2 & 8063 & 6642 & 0.08 & 0.002 & 1.87 & 0.03 & 0.19 \\
\hline & Case 3 & 6463 & 5169 & 0.22 & 0.001 & 0.41 & 0.08 & 0.13 \\
\hline
\end{tabular}

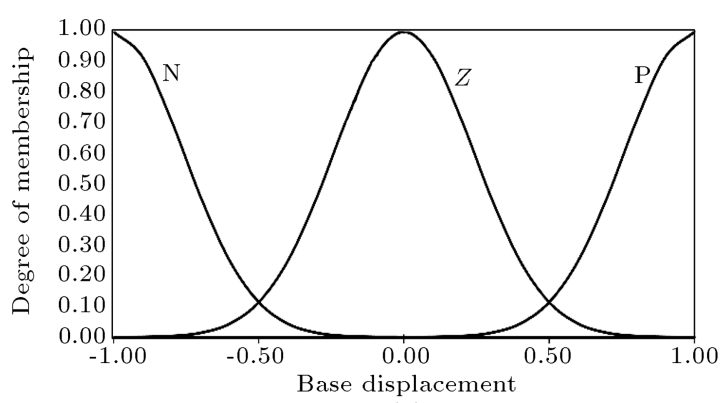

(a)

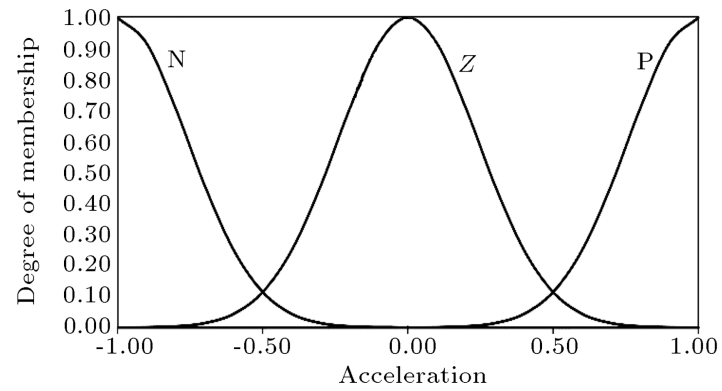

(b)

Figure 20. Membership functions for the input variable (base displacement and acceleration).

justified by factors such as the inability of the controller to create a proper current and time delay problem. Due to the non-designability of the adaptive isolator in a particular period and change of isolation stiffness and damping during the earthquake, the controller was unable to create a proper current during the peak time of the earthquake, leading to lack of proper stiffness and damping. Despite the varying stiffnesses and damping of the isolator during earthquakes, the adaptive isolator did not impose additional forces on the structure, hence better control over the structure and no increase in the floor accelerations and story drifts. The semi-active 
Table 8. Maximum structural responses for different control systems for the earthquake direction FPY-FNX.

\begin{tabular}{|c|c|c|c|c|c|c|c|c|}
\hline Earthquake & Control case & J1 & J2 & J3 & J4 & J5 & $\mathrm{J} 6$ & J7 \\
\hline \multirow{3}{*}{ Bam } & Case 1 & 50040 & 42040 & 0.79 & 0.011 & 2.83 & 0.21 & 0.68 \\
\hline & Case 2 & 50740 & 42270 & 0.50 & 0.011 & 3.48 & 0.07 & 0.44 \\
\hline & Case 3 & 27090 & 21660 & 0.52 & 0.005 & 1.99 & 0.12 & 0.26 \\
\hline \multirow{3}{*}{ Manjil } & Case 1 & 38830 & 32570 & 0.61 & 0.007 & 2.04 & 0.20 & 0.62 \\
\hline & Case 2 & 35690 & 31100 & 0.34 & 0.008 & 2.78 & 0.09 & 0.59 \\
\hline & Case 3 & 17350 & 14330 & 0.62 & 0.004 & 1.05 & 0.24 & 0.30 \\
\hline \multirow{3}{*}{ Tabas } & Case 1 & 67570 & 57680 & 1.38 & 0.017 & 4.18 & 0.59 & 1.69 \\
\hline & Case 2 & 56370 & 47850 & 0.62 & 0.014 & 4.02 & 0.20 & 1.06 \\
\hline & Case 3 & 86810 & 76550 & 0.94 & 0.022 & 5.83 & 0.38 & 1.43 \\
\hline \multirow{3}{*}{$\begin{array}{l}\text { Loma } \\
\text { Prieta }\end{array}$} & Case 1 & 3939 & 3469 & 0.05 & 0.001 & 0.28 & 0.02 & 0.08 \\
\hline & Case 2 & 3644 & 3222 & 0.04 & 0.001 & 0.63 & 0.01 & 0.06 \\
\hline & Case 3 & 2664 & 2207 & 0.09 & 0.001 & 0.17 & 0.03 & 0.05 \\
\hline \multirow{3}{*}{$\begin{array}{c}\text { San } \\
\text { Fernando }\end{array}$} & Case 1 & 839.4 & 706.1 & 0.01 & 0.001 & 0.05 & 0.01 & 0.02 \\
\hline & Case 2 & 1397 & 1217 & 0.001 & 0.001 & 0.37 & 0.001 & 0.06 \\
\hline & Case 3 & 651.1 & 573.4 & 0.03 & 0.001 & 0.15 & 0.02 & 0.01 \\
\hline \multirow{3}{*}{ Tabas } & Case 1 & 8859 & 7405 & 0.13 & 0.002 & 0.45 & 0.05 & 0.17 \\
\hline & Case 2 & 7164 & 5808 & 0.09 & 0.001 & 1.83 & 0.03 & 0.19 \\
\hline & Case 3 & 5903 & 4944 & 0.18 & 0.001 & 0.36 & 0.07 & 0.13 \\
\hline
\end{tabular}

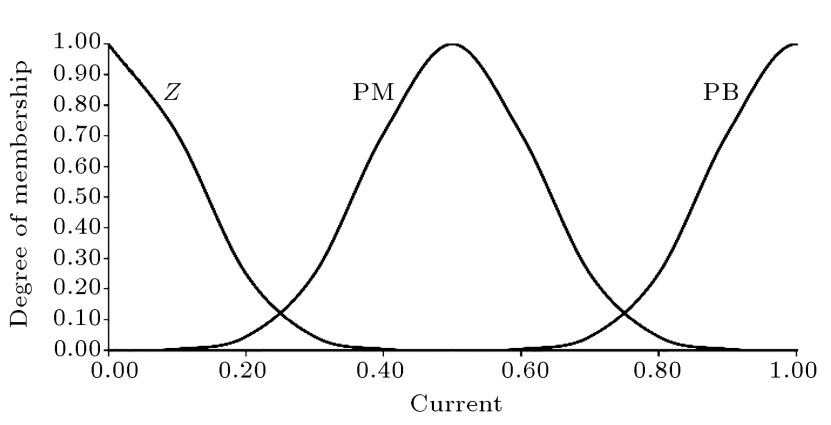

Figure 21. Membership functions for the output variable (current).

MR damper could efficiently control reducing the base displacement, but it increased floor accelerations and story drifts. According to the obtained results in the form of structural responses, it can be concluded that:

1. The semi-active MR damper outperformed both

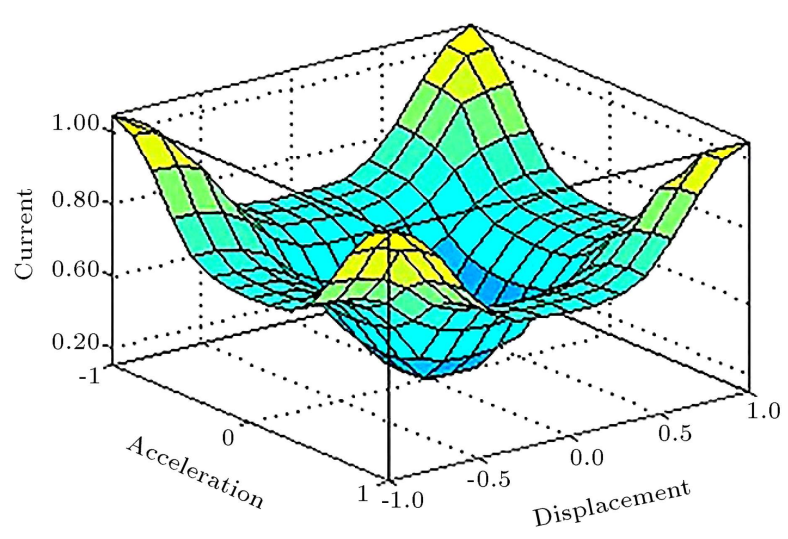

Figure 22. The surface of the fuzzy rules.

passive and adaptive isolators in reducing base displacement; however, the adaptive isolator was more successful in reducing base displacement than the passive isolator; 


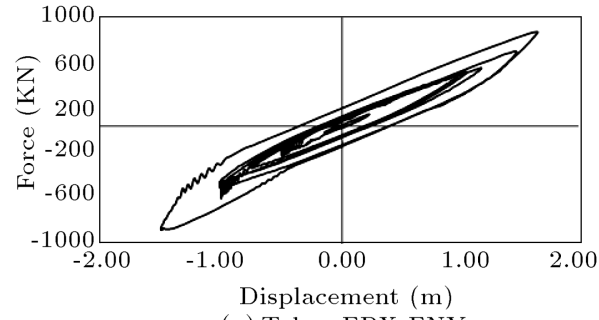

(a) Tabas FPX-FNY

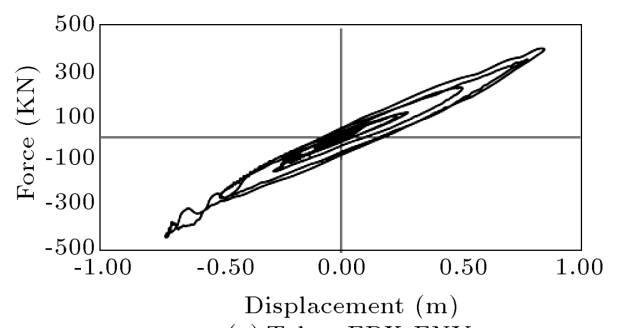

(c) Tabas FPX-FNY

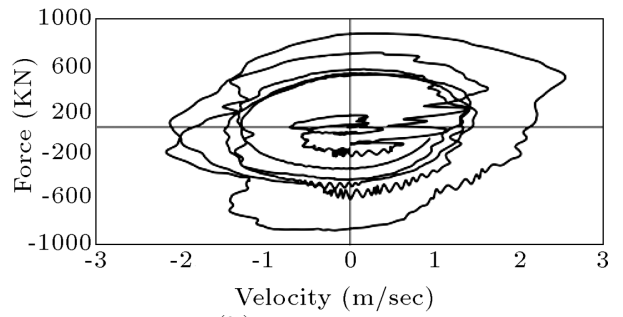

(b) Tabas FPX-FNY

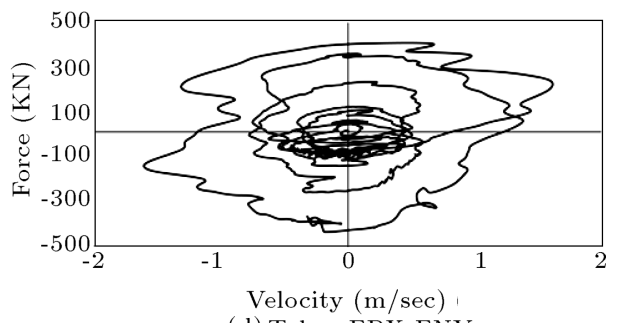

(d) Tabas FPX-FNY

Figure 23. The force displacement curve and force velocity curve of the Magnetorheological Elastomer (MRE) isolator (Tabas near-field earthquake).

Table 9. Response comparison of Magnetorheological Elastomer (MRE) and elastomeric isolators (percentage).

\begin{tabular}{ccccccccc}
\hline Earthquake & Direction & J1 & J2 & J3 & J4 & J5 & J6 & J7 \\
\hline $\begin{array}{c}\text { Average } \\
\text { near-field }\end{array}$ & FPX-FNY & -24.70 & -25.18 & -33.53 & -30.56 & -4.60 & -42.70 & -41.78 \\
& FPY-FNX & -24.24 & -23.92 & -21.96 & -21.03 & -12.99 & -19.78 & -42.88 \\
& & & & & & & & \\
$\begin{array}{c}\text { Average } \\
\text { far-field }\end{array}$ & FPX-FNY & -34.39 & -37.27 & 77.71 & -27.86 & 39.16 & 102.08 & -30.27 \\
\hline
\end{tabular}

Table 10. Response comparison of Magnetorheological Elastomer (MRE) isolator and the semi-active Magnetorheological (MR) damper (percentage).

\begin{tabular}{ccccccccc}
\hline Earthquake & Direction & J1 & J2 & J3 & J4 & J5 & J6 & J7 \\
\hline $\begin{array}{c}\text { Average } \\
\text { near-field }\end{array}$ & FPX-FNY & -12.90 & -14.21 & 2.27 & -24.99 & -20.62 & 44.79 & -26.87 \\
& FPY-FNX & -14.67 & -14.23 & 46.66 & -15.85 & -19.96 & 105.61 & -18.38 \\
& & & & & & & & \\
$\begin{array}{c}\text { Average } \\
\text { far-field }\end{array}$ & FPX-FNY & -34.36 & -38.01 & 310.45 & -30.68 & -62.24 & 739.80 & -34.59 \\
\hline
\end{tabular}

2. The adaptive isolator was the most successful controller in reducing roof acceleration;

3. The MRE isolator, in comparison with the elastomeric isolator, had better performance in nearfield earthquakes than in far-field earthquakes in reducing the base displacement, story drifts, and floor accelerations. For instance, the average of responses in near-field earthquakes indicated that the MRE isolator could reduce the base displacement
$(27.75 \%)$, floor acceleration $(8.80 \%)$, and story drift $(25.80 \%)$;

4. The semi-active MR damper for both far-field and near-field earthquakes could significantly control the reduction in base displacement, but it increased floor accelerations, story drifts, and story shear. For instance, the average of responses in near-field earthquakes indicated that the MRE isolator, in comparison with the semi-active MR damper, could 


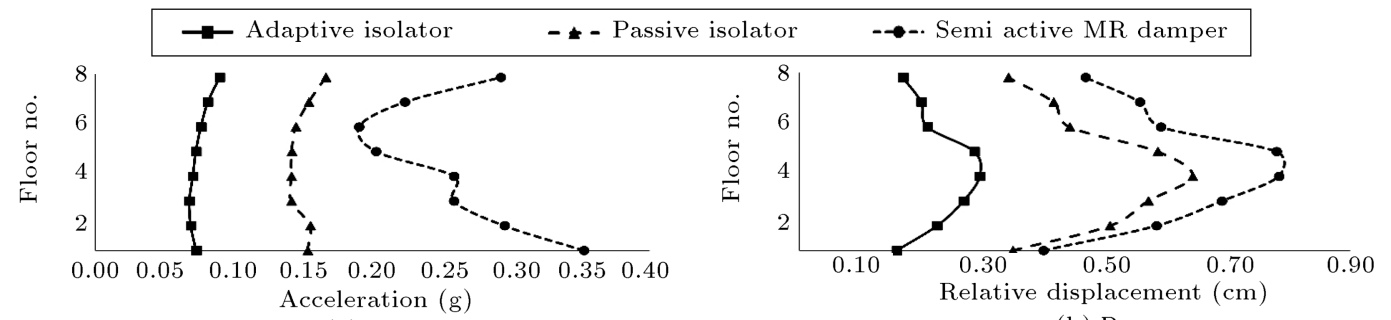

(a) Bam

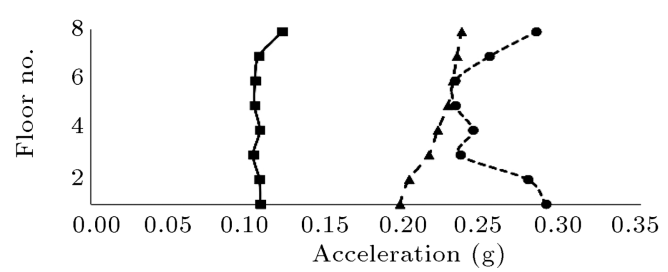

(c) Manjil

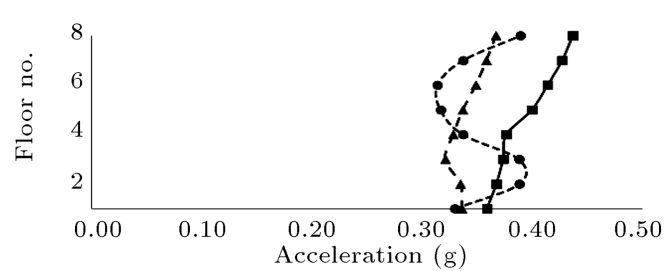

(e) Tabas
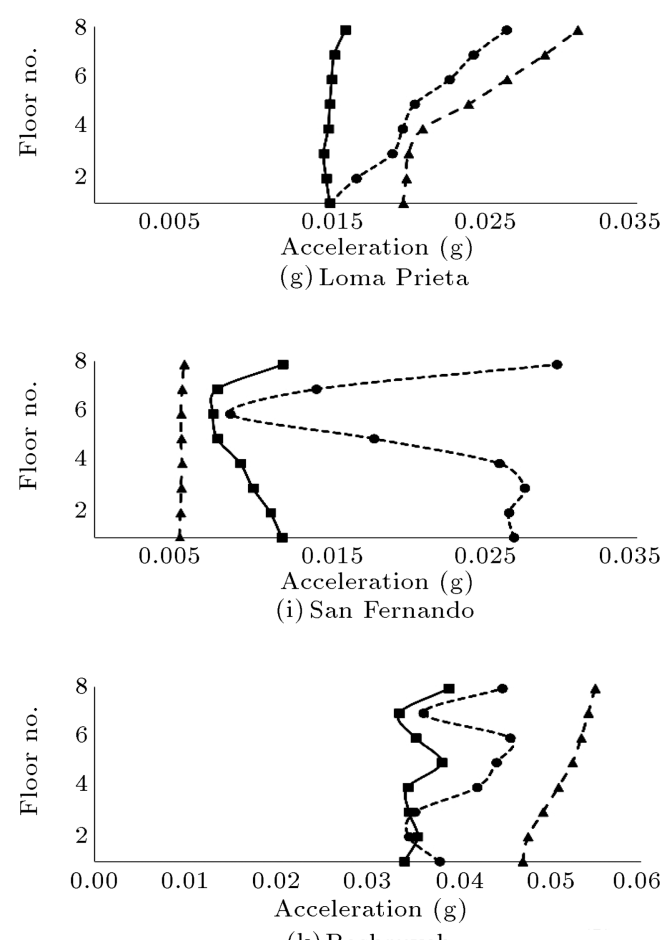

(k) Boshruyeh (d) Manjil

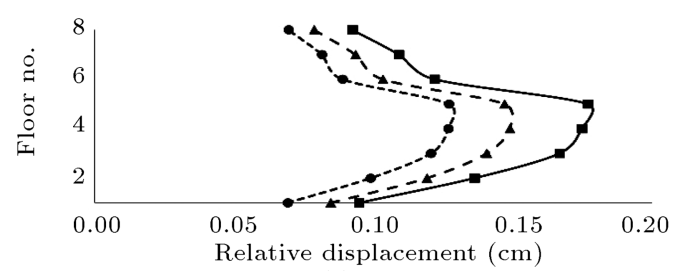

(f) Tabas

(h) Loma Prieta

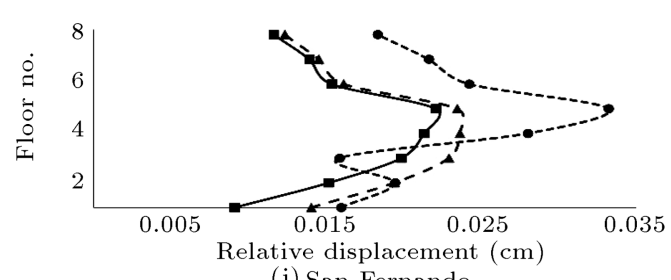

(j) San Fernando

(1) Boshruyeh
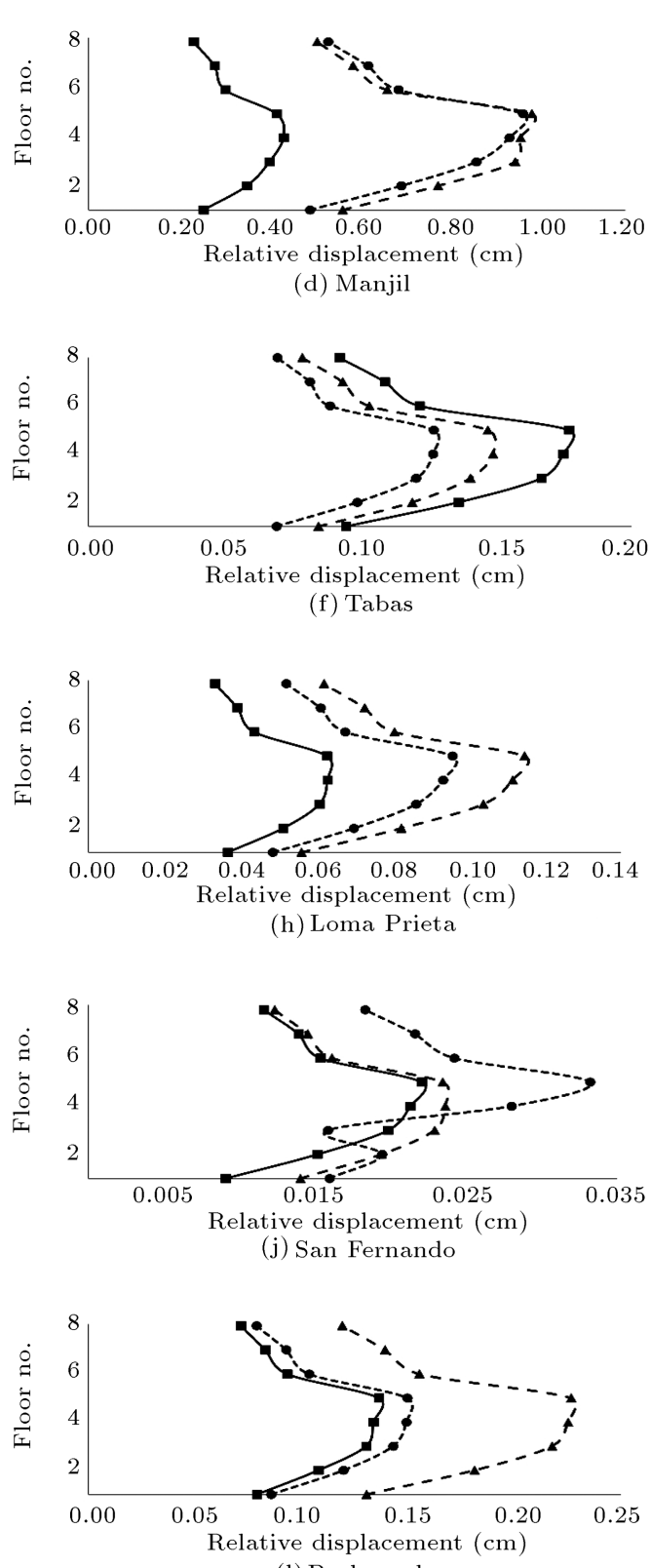

Figure 24. Maximum relative displacement and floor accelerations.

significantly increase base displacement to $24.47 \%$ while reducing floor acceleration and story drift to $20.29 \%$ and $20.42 \%$, respectively. The average responses of far-field earthquakes indicated that the MRE isolator, in comparison with the semi-active
MR damper, could increase base displacement to $293.07 \%$ while reducing floor acceleration and story drift to $66.30 \%$ and $31.63 \%$, respectively. Of note, the base displacement was lower in far-field earthquakes than that in near-field earthquakes; 


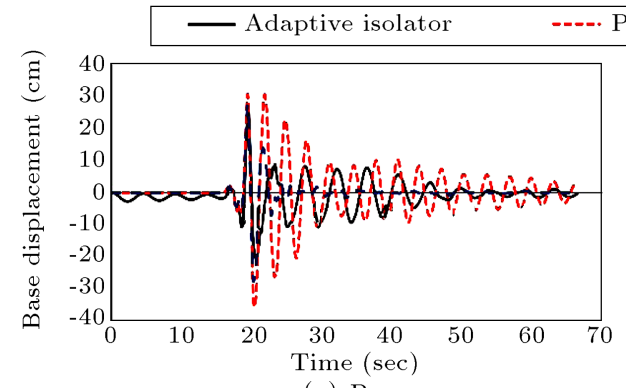

(a) Bam

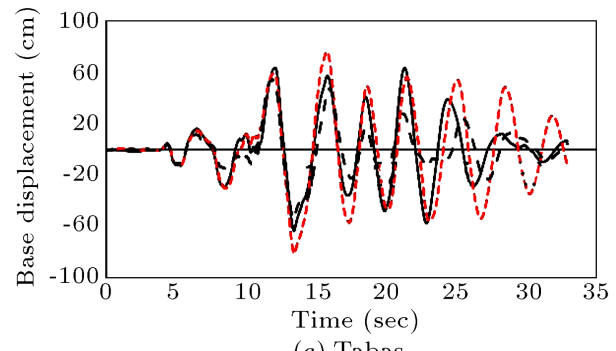

(c) Tabas
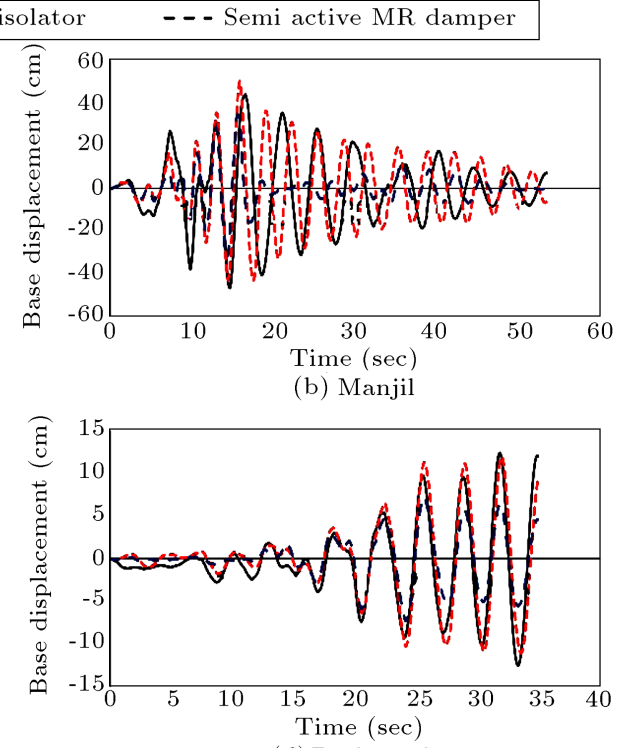

(d) Boshruyeh

Figure 25. Time history of base displacement.

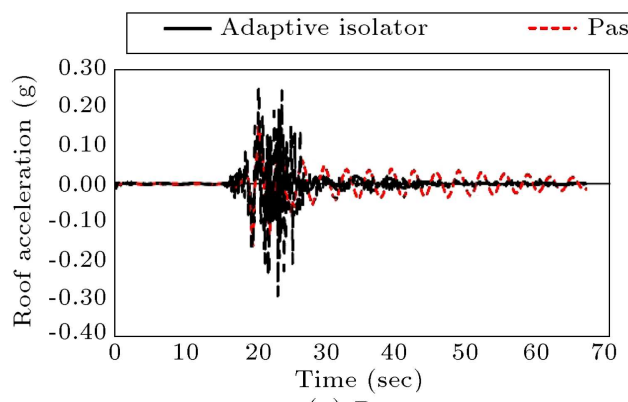

(a) Bam

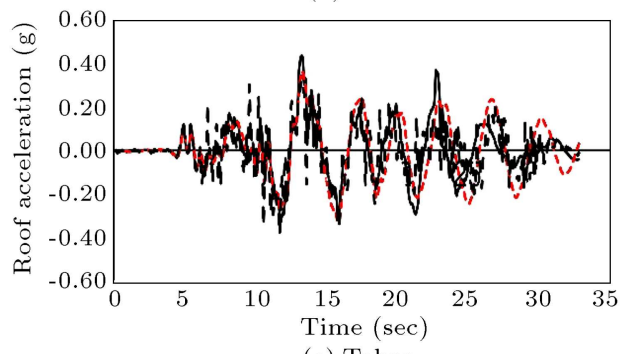

(c) Tabas

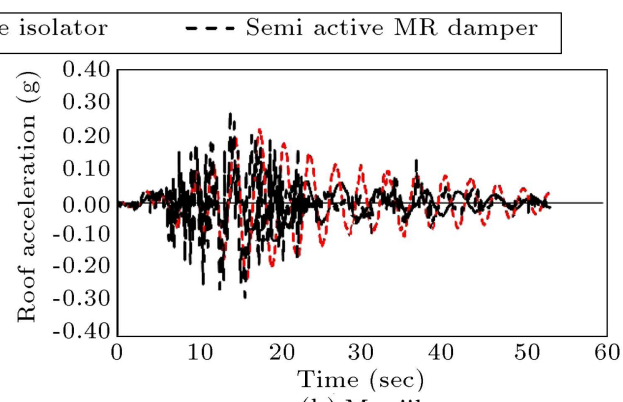

(b) Manjil

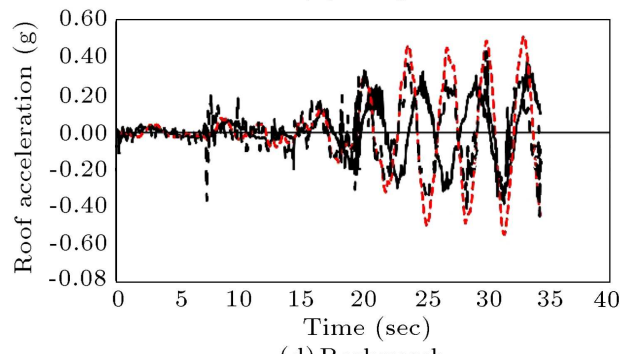

(d) Boshruyeh

Figure 26. Time history of roof acceleration.

for example, the maximum base displacement in near-field and far-field earthquakes was $138 \mathrm{~cm}$ and $22 \mathrm{~cm}$, respectively;

5. According to the results of this study, the MRE isolator was an appropriate substitute for MR damper. The MRE isolator could significantly reduce the base displacement without increasing other responses.

\section{References}

1. Naeim, F. and Kelly, J.M., Design of Seismic Isolated
Structures: From Theory to Practice, Wily (1999).

2. Komodromos, P., Seismic Isolation for Earthquake Resistant Structures, WIT Press/Computational Mechanics (2001).

3. Kelly, J.M. "Base isolation: linear theory and design", Earthq. Spectra, 6(2), pp. 223-244 (1990).

4. Kelly, J.M. "The current state of base isolation in the United States", 2th World Conf. on Structural Control, Kyoto, pp. 1043-1052 (1999).

5. Kelly, J.M. "Seismic isolation systems for developing countries", Earthq. Spectra, 18(3), pp. 385-406 (2002). 
6. Morgan, T.A. "The use of innovative base isolation systems to achieve complex seismic performance objectives", PhD Dissertation University of California, Berkeley (2007).

7. Pan, P., Zamfirescu, D., Nakashima, M., Nakayasu, N., and Kashiwa, H. "Base-isolation design practice in Japan: introduction to the post-Kobe approach", $J$. Earthq. Eng., 9(1), pp. 147-171 (2005).

8. Kim, H.S., Roschke, P.N., Lin, P.Y., and Loh, C.H. "Neuro-fuzzy model of hybrid semi-active base isolation system with FPS bearings and an MR damper", Eng. Struct., 28(7), pp. 947-958 (2006).

9. Spencer Jr, B.F. and Nagarajaiah, S. "State of the art of structural control", J. Struct. Eng., 129(7), pp. 845-856 (2003).

10. Jangid, R.S. and Kelly, J.M. "Base isolation for nearfault motions", Earthq. Eng. Struct. Dyn., 30(5), pp. 691-707 (2001).

11. Mazza, F. and Vulcano, A. "Effects of near-fault ground motions on the nonlinear dynamic response of base-isolated R C framed buildings", Earthq. Eng. Struct. Dyn., 41(2), pp. 211-232 (2011).

12. Nagarajaiah, S., Narasimhan, S., and Johnson, E. "Structural control benchmark problem: phase IInonlinear smart base-isolated building subjected to near fault earthquakes", J. Struct. Control Health Monit., 15(5), pp. 653-656 (2008).

13. Chopra, A.K. and Chintanapakdee, C. "Comparing response of SDF systems to near-fault and far-fault earthquake motions in the context of spectral regions", Earthq. Eng. Struct. Dyn., 30(12), pp. 1769-1789 (2001).

14. Abdalla, J.A., Petrovski, J.T., and Mohamedzein, Y.E. "Vibration characteristics of a far-field earthquake and its shaking effects on Dubai emerging skycrapers", 14th World Conf. on Earthquake Engineering, Beijing, China (2008).

15. Kelly, J.M. "The role of damping in seismic isolation", Earthq. Eng. Struct. Dyn., 28(1), pp. 3-20 (1999).

16. Yaghmaei-Sabegh, S., Safari, S., and Abdolmohammad, K. "Characterization of ductility and inelastic displacement demand in base-isolated structures considering cyclic degradation", J. Earthq. Eng., 23(4), pp. 557-591 (2019).

DOI: $10.1080 / 13632469.2017 .1326415$

17. Yaghmaei-Sabegh, S., Safari, S., and Abdolmohammad, K. "Estimation of inelastic displacement ratio for base-isolated structures", Earthq. Eng. Struct. Dyn., 47(3), pp. 634-659 (2018). DOI: 10.1002/eqe.2983

18. Rofooei, F.R. and Ebrahimi, M. "Evaluation of the vertical distribution of base shear force in base-isolated structures", Scientia Iranica, 14(1), pp. 11-22 (2007).

19. Kelly, J.M. "Base isolation: origins and development", EERC News (1991).

20. Ronbinson, W.H. "Lead-Rubber hysteretic bearings suitable for protecting structures during earthquakes", Earthq. Eng. Struct. Dyn., 10(4), pp. 593-604 (1982).
21. Fuller, K.N.G., Gough, J., Pond, T.J., and Ahmadi, H.R. "High damping natural rubber seismic isolators", J. Struct. Control Health Monit., 4(2), pp. 19-40 (1997).

22. Lu, L.Y. and Lin, G.L. "Fuzzy friction controllers for semi-active seismic isolation systems", J. Intell. Mater. Syst. Struct., 20(14), pp. 1747-1770 (2009).

23. Yang, J.N. and Agrawal, A.K. "Semi-active hybrid control systems for nonlinear buildings against nearfield earthquakes", Eng. Struct., 24(3), pp. 271-280 (2002).

24. Lin, P.Y., Roschke, P.N., and Loh, C.H. "Hybrid base isolation with magneto-rheological damper and fuzzy control", J. Struct. Control Health Monit., 14(3), pp. 384-405 (2006).

25. Malekzadeh, M. and Taghikhany, T. "Adaptive behavior of double concave friction pendulum bearing and its advantages over friction pendulum systems", Scientia Iranica, Transactions A: Civil Engineering, 17(2), pp. 81-88 (2010).

26. Popp, K., Kroger, M., Li, W., Zhang, X., and Kosasih, P.B. "MRE properties under shear and squeeze modes and applications", J. Intell. Mater. Syst. Struct., 21(15), pp. 1471-1477 (2010).

27. Li, W.H., Zhou, Y., and Tian, T.F. "Viscoelastic properties of MR elastomers under harmonic loading", Rheol. Acta, 49(7), pp. 733-740 (2010).

28. Li, W.H., Zhang, X.Z., Du, H., and Chen, D.F. "Enhance MR elastomer performance with nano particles additives", 3th Asia-Pacific Conf. Transducers and Micro/Nanotechnology, Singapore (2006).

29. Abramchuk, S.S., Grishin, D.A., Kramarenko, E.Y., Stepanov, G.V., and Khokhlov, A.R. "Effect of a homogeneous magnetic field on the mechanical behavior of soft magnetic elastomers under compression Polym", Sci. Ser. A Polym. Phys., 48(2), pp. 138-145 (2006).

30. Chen, L., Gong, X.L., and Li, W.H. "Damping of magnetorheological elastomers", Chin. J. Chem. Phys., 21(6), pp. 581-585 (2008).

31. Behrooz, M., Wang, X.J., and Gordaninejad, F. "A semi-active/passive isolator", 5th World Conf. on Struct. Control Monit., Shinjuku, Tokyo, p. 049 (2010).

32. Opie, S. and Yim, W. "Design and control of a real-time variable stiffness vibration isolator", IEEE/ASME Int. Conf. Advanced Intelligent Mechatronics, Singapore, pp. 380-385 (2009).

33. Li, Y., Li, J., Li, W., and Samali, B. "Development and characterization of a magnetorheological elastomer based adaptive seismic isolator", Smart Mater. Struct., 22(3), pp. 1-12 (2013).

34. Li, Y. and Li, J. "A highly adjustable base isolator utilizing magnetorheological elastomer: Experimental testing and modeling", J. Vib. Acoust., 137(1), 011009 (2015). 
35. Li, Y., Li, J., Tian, T., and Li, W. "A highly adjustable magnetorheological elastomer base isolator for applications of real-time adaptive control", Smart Mater. Struct., 22(9), pp. 1-18 (2013).

36. Zhao, L., Yu, M., Fu, J., Zhu, M., and Li, B. "A miniature MRE isolator for lateral vibration suppression of bridge monitoring equipment: design and verification", Smart Mater. Struct., 26(4), 047001 (2017).

37. Gu, X., Li, J., and Li, Y. "Adaptive base isolation system with magneto rheological elastomer base isolators: Numerical investigations", 6th World Conf. on Structural Control and Monitoring, 1, Barcelona, Spain (2014).

38. Gu, X., Li, J., Li, Y., and Askari, M. "Frequency control of smart base isolation system employing A novel adaptive magneto-rheological elastomer base isolator", J. Intell. Mater. Sys. Struct., 27(7), pp. 849$858(2015)$.

39. Gu, X., Li, J., and Li, Y. "Innovative semiactive storey isolation system utilising novel magnetorheological elastomer base isolators", In ST Smith (Ed.), 23rd Australasian Conf. on the Mechanics of Structures and Materials (ACMSM23), 2, Byron Bay, NSW, 9-12 December, Southern Cross University, Lismore, NSW, pp. 925-930 (2014).

40. Gu, X., Li, Y., and Li, J. "Investigations on response time of magnetorheological elastomer isolator for realtime control implementation", Smart Mater. Struct., 25(11), 11L04 (2016).

41. Yang, J., Sun, S., Tian, T.F., Li, W., Du, H., Alici, G., and Nakano, M. "Development of a novel multi-layer MRE isolator for suppression of building vibrations under seismic events", Mech. Syst. and Signal Processing, 70(71), pp. 811-820 (2016).

42. Jolly, M.R., Carlson, J.D., and Munoz, B.C. "A model of the behaviour of magnetorheological materials", Smart Mater. Struct., 5(5), pp. 607-614 (1996).

43. Davis, L.C. "Model of magnetorheological elastomers", J. Applied Phys, 85(6), pp. 3348-3351 (1999).

44. Gu, X., Yu, Y., Li, J., and Li, Y. "Semi-active control of magnetorheological elastomer base isolation system utilising learning-based inverse model", Journal of Sound and Vibration, 406, pp. 346-362 (2017).

45. Li, W.H., Zhang, X.Z., and Du, H. "Magnetorheological elastomers and their applications", In P.M. Visakh, S. Thomas, A.K. Chandra and A.P. Mathew (Eds.), Advances in Elastomers I: Blends and Interpenetrating Networks, Berlin, Germany: Springer, pp. 357-374 (2013).

46. Yang, J., Du, H., Li, W., Li, Y., Li, J., Sun, S., and deng, H.X. "Experimental study and modeling of a novel magnetorheological elastomer isolator", Smart Mater. Struct., 22(11), pp. 1-14 (2013).

47. Narasimhan, S., Nagarajaiah, S., Gavin, H.P., and Johnson, E.A. "Smart base isolated benchmark building part I: problem definition", J. Struct. Control and Health Monit., 13(2-3), pp. 573-588 (2006).
48. Nagarajaiah, S. and Narasimhan, S. "Smart base isolated benchmark building part II: phase I sample controllers for linear isolation system", J. Struct. Control Health Monit., 13(2-3), pp. 589-604 (2006).

49. Erkus, B. and Johnson, E.A. "Smart base isolated benchmark building part III: a sample controller for bilinear isolation", J. Struct. Control Health Monit., 13(2-3), pp. 605-625 (2006).

50. Narasimhan, S., Nagarajaiah, S., and Johnson, E.A. "Smart base isolated benchmark building part IV: phase II. Sample controller for nonlinear isolation systems", J. Struct. Control Health Monit., 15(5), pp. 657-672 (2008).

51. Sharma, A. and Jangid, R.S. "Seismic response of base-isolated benchmark building with variable sliding isolators", J. Earthq. Eng., 14(7), pp. 1063-1091 (2010).

52. Li, Y., Li, J., and Li, Y., Adaptive MRE Vibration Isolation Assembly and System, University of Technology, Sydney (2014).

53. Harvey Jr, P.S. and Gavin, H.P. "Truly isotropic biaxial hysteresis with arbitrary knee sharpness", Earthq. Eng. Struct. Dyn., 43(13), pp. 2051-2057 (2014).

54. Spencer Jr, B.F., Dyke, S.J., Sain, M.K., and Carlson, J.D. "Phenomenological model of a magnetorheological damper", J. Eng. Mech., 123(3), pp. 230-238 (1997).

55. Choi, S.B., Lee, S.K., and Park, Y.P. "A hysteresis model for field-dependent damping force of a magnetorheological damper", J. Sound Vib., 245(2), pp. 375-383 (2001).

56. Jung, H.J., Spencer Jr, B.F., and Lee, I.W. "Control of seismically excited cable-stayed bridge employing magnetorheological fluid dampers", J. Struct. Eng., 129(7), pp. 873-883 (2003).

57. Zapateiro, M., Karimi, H.R., Luo, N., Phillips, B.M., and Spencer Jr, B.F. "Semiactive backstepping control for vibration reduction in a structure with magnetorheological damper subject to seismic motions", J. Intell. Mater. Sys. Struct., 20(17), pp. 2037-2053 (2009).

58. Jangid, R.S. and Kelly, J.M. "Base isolation for nearfault motions", Earthquake Eng. Struct. Dyn., 30, pp. 691-707 (2001).

59. Reigles, D.G. and Symans, M.D. "Supervisory fuzzy control of a base isolated benchmark building utilizing a neuro-fuzzy model of controllable fluid viscous dampers", J. Struct. Control Health Monit., 13, pp. 724-747 (2006).

60. Kim, H.S. and Roschke, P.N. "GA-fuzzy control of smart base isolated benchmark building using supervisory control technique", Advances in Engineering Software, 38(7), pp. 453-465 (2007).

\section{Biographies}

Saeed Taghizadeh is a PhD student of Structural Engineering at Ferdowsi University of Mashhad (FUM). 
He received his MSc degree from FUM in 2013. His research interests are earthquake engineering and structural control.

Abbas Karamodin received his BSc and $\mathrm{MSc}$ degrees in Structural Engineering from the University of Tehran (UT) in 1986 and his PhD degree in Structural
Engineering from Ferdowsi University of Mashhad (FUM) in 2009 with a minor in Structural Control. He has been serving in FUM as a faculty member since 1987. He has published 3 books in his related field and more than 10 papers in respected journals and conference proceedings. His research interests include earthquake engineering and structural control. 